\title{
Tuning the equatorial crystal-field in mononuclear Dy(III) complexes to improve single-molecule magnet properties
}

\author{
Li Zhu, Bing Yin, ${ }^{\dagger *}$ Pengtao Ma, ${ }^{\lceil}$and Dongfeng $\mathrm{Li}^{\dagger *}$
}

$\dagger$ Key Laboratory of Pesticide \& Chemical Biology, Ministry of Education, College of Chemistry, Central China Normal University, Wuhan 430079, P. R. China. E-mail: dfli@mail.ccnu.edu.cn

Key Laboratory of Synthetic and Natural Functional Molecule of the Ministry of Education, College of Chemistry and Materials Science, Northwest University, Xi'an 710127, P. R. China. E-mail: rayinyin@nwu.edu.cn

『Henan Key Laboratory of Polyoxometalate Chemistry, College of Chemistry and Chemical Engineering, Henan University, Kaifeng, Henan 475004, P. R. China. 


\section{Content}

$\begin{array}{ll}\text { 1. Materials and measurements } & \text { S3 }\end{array}$

2. Syntheses of the ligands and complexes $\quad$ S3

3. Collection of Dy based SMMs S4

4. Single crystal X-ray crystallographic data S5

$\begin{array}{lr}\text { 5. Crystal Structure } & \text { S9 }\end{array}$

6. Magnetic Measurements $\quad \mathbf{S 1 0}$

$\begin{array}{ll}\text { 7. Theory Calculations } & \text { S18 }\end{array}$

8. References $\quad$ S25 


\section{Materials and measurements}

General Procedure.

All reactions and manipulations described below were performed under aerobic conditions. The ligand N,N'-bis(2-hydroxybenzyl)-N,N'-bis(5-fluoro-2-methylpyridyl)ethylenediamine $\left(\mathrm{H}_{2}\right.$ bbpen-F) was prepared in excellent yield according to the reported methods. Metal salts and other reagents were commercially available and used as received without further purification. The C, H, and N microanalyses were carried out with a Perkin-Elmer 240Q elemental analyzer. The FT-IR spectra were recorded from $\mathrm{KBr}$ pellets in the range $4000-400 \mathrm{~cm}^{-1}$ on a Bruker Tensor 27 spectrophotometer. The mass spectrometer was operated with a Finnigan LCQ Advantage MAX (m/z: 50-2000) under the positive ion mode with the ESI source. Powder Xray diffraction patterns (PXRD) were measured at $296 \mathrm{~K}$ on a Bruker AXS D8 Advance powder diffractometer at $40 \mathrm{kV}, 40 \mathrm{~mA}$ for $\mathrm{Cu}-\mathrm{K} \alpha(\lambda=1.5406 \AA)$. The polycrystalline samples were isolated via filtration from the mother liquor and left to air-dry on a filter paper and measured. Magnetic susceptibility measurements were performed on a Quantum Design MPMS SQUIDVSM or MPMS XL-7 magnetometer during cooling and applied magnetic field of 1000 Oe. All data were corrected for the diamagnetic contribution calculated from Pascal constants.

\section{Syntheses of the ligands and complexes}

\section{Synthesis of the $\mathrm{H}_{2}$ bbpen-F}

Ethylenediamine $(1.2 \mathrm{~g}, 20 \mathrm{mmol})$ was added to a solution of salicylaldehyde $(4.8 \mathrm{~g}, 40$ $\mathrm{mmol})$ in methanol $(100 \mathrm{~mL})$, After reflux $3 \mathrm{~h}$ the solution was cooled to room temperature. $\mathrm{NaBH}_{4}(1.82 \mathrm{~g}, 48 \mathrm{mmol})$ in $10 \mathrm{~mL}$ of methanol was added. The solution was refluxed overnight. The precipitate was filtered off, washed with water, dried in vacuum and the crude $\mathrm{H}_{2}$ bben was obtained. A solution of 2-(bromomethyl)-5-fluoropyridine hydrobromide (2.79 $\mathrm{g}$, $10 \mathrm{mmol})$ dissolved in water $(30 \mathrm{~mL})$, and added the $2 \mathrm{M} \mathrm{NaOH}$, to adjust the $\mathrm{pH}$ to $8-9$, the $\mathrm{H}_{2}$ bben (1.36 g, $5 \mathrm{mmol}$ ) was added with stirring. The mixing reaction was then heated to $65^{\circ} \mathrm{C}$ and $\mathrm{NaOH}(2 \mathrm{M})$ was added during over a period of $1 \mathrm{~h}$ in small batches so that the $\mathrm{pH}$ never exceeded 10. The red solution was cooled and extracted with chloroform $(10 \times 70 \mathrm{~mL})$. The organic phase was dried over anhydrous $\mathrm{Na}_{2} \mathrm{SO}_{4}$. The solvent was removed under vacuum. a red residue was obtained. The crude was purified by Chromatography on silica gel (DCM/PE $=2: 1, \mathrm{v} / \mathrm{v}$ ) to yield the product as a white solid, $2.04 \mathrm{~g}$, yield: $67 \%$. ESI-MS: m/z $=491.2$ $\left([\mathrm{M}+\mathrm{H}]^{+}\right) .{ }^{1} \mathrm{H} \mathrm{NMR}\left(400 \mathrm{MHz}, \mathrm{CDCl}_{3}\right), \delta=10.44(\mathrm{~s}, 2 \mathrm{H}), 8.39(\mathrm{~d}, \mathrm{~J}=2.8 \mathrm{~Hz}, 2 \mathrm{H}), 7.33(\mathrm{td}, \mathrm{J}$ 
$=8.4,2.9 \mathrm{~Hz}, 2 \mathrm{H}), 7.19-7.12(\mathrm{~m}, 4 \mathrm{H}), 6.89(\mathrm{dd}, \mathrm{J}=7.3,1.1 \mathrm{~Hz}, 2 \mathrm{H}), 6.82-6.72(\mathrm{~m}, 4 \mathrm{H})$, $3.71(\mathrm{~s}, 4 \mathrm{H}), 3.68(\mathrm{~s}, 4 \mathrm{H}), 2.73(\mathrm{~s}, 4 \mathrm{H})$.

Synthesis of [Dy(bbpen-F)Cl] (1). To a solution of $\mathrm{H}_{2}$ bbpen-F $(24.5 \mathrm{mg}, 0.05 \mathrm{mmol})$ in acetonitrile $(6 \mathrm{~mL})$ was added triethylamine $(20.4 \mathrm{mg}, 0.2 \mathrm{mmol})$. After stirring for $5 \mathrm{~min}$, the $\mathrm{DyCl}_{3}(13.4 \mathrm{mg}, 0.05 \mathrm{mmol})$ solid was added to generate a slightly white suspension, which was sealed in a $23 \mathrm{~mL}$ Teflon-lined stainless container and kept at $70{ }^{\circ} \mathrm{C}$ for 3 day and then cooled slowly to room temperature. A colorless block crystals were obtained with the yield ca. $57 \%$ (based on the Dy(III) salt). Anal. Calcd (\%) for $\left(\mathrm{C}_{28} \mathrm{H}_{26} \mathrm{ClDyF}_{2} \mathrm{~N}_{4} \mathrm{O}_{2}\right): \mathrm{C}, 48.99 ; \mathrm{H}$, $3.82 ; \mathrm{N}, 8.16$. Found: C, 49.07; H, 3.87; N, 8.23.

Synthesis of [Dy(bbpen-F)Br] (2). A synthetic procedure similar to that for complex 1 was used to synthesize complex 2 except that $\mathrm{DyCl}_{3}$ was replaced by anhydrous $\mathrm{DyBr}_{3}(20.1 \mathrm{mg}$, $0.05 \mathrm{mmol}$ ) and triethylamine $(15.3 \mathrm{mg}, 0.15 \mathrm{mmol})$. Yield: $49 \%$ (based on the Dy(III) salt). Anal. Calcd (\%) for $\left(\mathrm{C}_{28} \mathrm{H}_{26} \mathrm{BrDyF}_{2} \mathrm{~N}_{4} \mathrm{O}_{2}\right)$ : C, 46.01; H, 3.59; N,7.67. Found: C, 46.14; H, 3.67; N, 7.85 .

\section{Collection of Dy based SMMs}

Table S1 Collection of Dy based SMMs from literature

\begin{tabular}{|c|c|c|c|c|}
\hline Ln-SMMs & $\overline{U_{\text {eff }} / \mathrm{K}}$ & $\tau_{0} / \times 10^{-12} \mathrm{~s}$ & $T_{\mathrm{B}} / \mathrm{K}$ & ref \\
\hline [Dy(bbpen)Br] & 1025 & 4.21 & 14 & $17 \mathrm{a}$ \\
\hline$\left[\mathrm{Dy}\left(\right.\right.$ bbpen- $\left.\left.\mathrm{CH}_{3}\right) \mathrm{Br}\right]$ & 1162 & 1.02 & 15 & $19 \mathrm{a}$ \\
\hline$\left[\mathrm{Dy}\left(\mathrm{O}^{\mathrm{t}} \mathrm{Bu}\right)_{2}(\mathrm{py})_{5}\right]\left[\mathrm{BPh}_{4}\right]$ & 1815 & 1.17 & 14 & $18 \mathrm{a}$ \\
\hline$\left[\mathrm{Dy}((\mathrm{S})-(-)-1-\text { phenylethanol })_{2}(\mathrm{py})_{5}\right]\left[\mathrm{BPh}_{4}\right]$ & 1655 & 1.3 & 22 & $18 \mathrm{c}$ \\
\hline$\left[\left(\eta^{5}-\mathrm{C} \mathrm{p}^{\mathrm{iPr} 5}\right) \mathrm{Dy}\left(\eta^{5}-\mathrm{Cp}^{*}\right)\left(\mathrm{BH}_{4}\right)\right]$ & 2218 & 4.2 & 80 & $7 b$ \\
\hline$\left[\mathrm{Dy}\left(\mathrm{Cp}^{\mathrm{iPr} 4 \mathrm{Me}}\right)_{2}\right]\left[\mathrm{B}\left(\mathrm{C}_{6} \mathrm{~F}_{5}\right)_{4}\right]$ & 2113 & - & 62 & 11 \\
\hline$\left[\mathrm{Dy}\left(\mathrm{Cp}^{\mathrm{ttt}}\right)_{2}\right]\left[\mathrm{B}\left(\mathrm{C}_{6} \mathrm{~F}_{5}\right)_{4}\right]^{[13 \mathrm{a}]}$ & 1760 & 19.86 & 60 & $13 \mathrm{a}$ \\
\hline$\left[\mathrm{Dy}\left(\mathrm{OCMe}_{3}\right)_{2}(\mathrm{py})_{5}\right] \mathrm{BPh}_{4}$ & 1859 & 1.38 & 25 & $18 \mathrm{~b}$ \\
\hline$\left[\mathrm{Dy}(\mathrm{Dtp})_{2}\right]\left[\mathrm{Al}\left\{\mathrm{OC}\left(\mathrm{CF}_{3}\right)_{3}\right\}_{4}\right]$ & 1760 & 2 & 48 & $13 b$ \\
\hline$\left[\mathrm{Dy}\left(\mathrm{Cy}_{3} \mathrm{PO}\right)_{2}\left(\mathrm{H}_{2} \mathrm{O}\right)_{5}\right] \mathrm{Br}_{3} \cdot 2\left(\mathrm{Cy}_{3} \mathrm{PO}\right) \cdot 2 \mathrm{H}_{2} \mathrm{O} \cdot 2 \mathrm{EtOH}$ & 543 & 20 & 20 & $17 \mathrm{~b}$ \\
\hline
\end{tabular}




\section{Single crystal X-ray crystallographic data}

Table S2. Crystal data and structure refinement for complexes $\mathbf{1}$ and $\mathbf{2 .}$

\begin{tabular}{|c|c|c|}
\hline Complex & 1 & 2 \\
\hline Formula & $\mathrm{C}_{28} \mathrm{H}_{26} \mathrm{ClDyF}_{2} \mathrm{~N}_{4} \mathrm{O}_{2}$ & $\mathrm{C}_{28} \mathrm{H}_{26} \mathrm{BrDyF}_{2} \mathrm{~N}_{4} \mathrm{O}_{2}$ \\
\hline Formula weight & 686.48 & 730.94 \\
\hline Temperature / K & 296 & 296 \\
\hline Crystal system & Orthorhombic & Orthorhombic \\
\hline Space group & $P$ ben & $P b c n$ \\
\hline$a / \AA$ & $8.6667(14)$ & $8.6721(12)$ \\
\hline$b / \AA$ & $17.812(3)$ & $17.877(2)$ \\
\hline$c / \AA$ & $16.988(3)$ & $17.072(2)$ \\
\hline$\alpha /^{\circ}$ & 90.00 & 90.00 \\
\hline$\beta /{ }^{\circ}$ & 90.00 & 90.00 \\
\hline$\gamma / \circ$ & 90.00 & 90.00 \\
\hline$V / \AA^{3}$ & $2622.5(7)$ & $2646.7(6)$ \\
\hline$Z$ & 4 & 4 \\
\hline$F(000)$ & 1356 & 1428 \\
\hline$d_{\text {calc }} / \mathrm{Mg} \mathrm{m}^{-3}$ & 1.739 & 1.834 \\
\hline Mo Ka / & 0.71073 & 0.71073 \\
\hline Reflections collected & 20244 & 23820 \\
\hline Independent reflections & 3173 & 3601 \\
\hline$R_{1}[I>2 \sigma(I)]$ & 0.0295 & 0.0230 \\
\hline$w R_{2}[I>2 \sigma(I)]$ & 0.0722 & 0.0439 \\
\hline$R_{1}{ }^{\mathrm{a}}$, (all data) & 0.0373 & 0.0388 \\
\hline$w R_{2}^{\mathrm{b}}$, (all data) & 0.0803 & 0.0520 \\
\hline Goodness-of-fit on $F^{2}$ & 1.23 & 1.11 \\
\hline
\end{tabular}

${ }^{\mathrm{a}} R_{1}=\Sigma\left(\mathrm{F}_{\mathrm{o}}-\mathrm{F}_{\mathrm{c}}\right) / \Sigma \mathrm{F}_{\mathrm{o}} \cdot{ }^{\mathrm{b}} w R_{2}=\left[\Sigma w\left(\mathrm{~F}_{\mathrm{o}}{ }^{2}-\mathrm{F}_{\mathrm{c}}{ }^{2}\right)^{2} / \Sigma w\left(\mathrm{~F}_{\mathrm{o}}\right)^{2}\right]^{1 / 2 \mathrm{a}}$ 
Table S3. Selected bond lengths $(\AA)$ and angles $\left(^{\circ}\right)$ for complexes $\mathbf{1}$ and 2.

\begin{tabular}{|c|c|c|c|}
\hline \multicolumn{2}{|c|}{1} & \multicolumn{2}{|c|}{2} \\
\hline \multicolumn{2}{|c|}{ Bond lengths around Dy(1) } & \multicolumn{2}{|c|}{ Bond lengths around Dy(1) } \\
\hline Dy(1)-O(1) & $2.160(2)$ & $\mathrm{Dy}(1)-\mathrm{O}(1)$ & $2.155(2)$ \\
\hline $\operatorname{Dy}(1)-\mathrm{N}(1)$ & $2.568(3)$ & $\operatorname{Dy}(1)-\mathrm{N}(1)$ & $2.583(2)$ \\
\hline $\operatorname{Dy}(1)-\mathrm{N}(2)$ & $2.585(3)$ & $\operatorname{Dy}(1)-\mathrm{N}(2)$ & $2.578(2)$ \\
\hline $\operatorname{Dy}(1)-\mathrm{Cl}(1)$ & $2.6680(14)$ & $\operatorname{Dy}(1)-\operatorname{Br}(1)$ & $2.8462(6)$ \\
\hline \multicolumn{2}{|c|}{ Bond angles including Dy(1) } & \multicolumn{2}{|c|}{ Bond angles including Dy(1) } \\
\hline $\mathrm{O}(1)-\mathrm{Dy}(1)-\mathrm{O}(1 \mathrm{~A})$ & $156.82(13)$ & $\mathrm{O}(1)-\mathrm{Dy}(1)-\mathrm{O}(1 \mathrm{~A})$ & $157.52(11)$ \\
\hline $\mathrm{O}(1)-\mathrm{Dy}(1)-\mathrm{N}(1)$ & $95.06(10)$ & $\mathrm{O}(1)-\mathrm{Dy}(1)-\mathrm{N}(1)$ & $95.12(8)$ \\
\hline $\mathrm{O}(1)-\mathrm{Dy}(1)-\mathrm{N}(2)$ & $77.02(9)$ & $\mathrm{O}(1)-\mathrm{Dy}(1)-\mathrm{N}(2)$ & $77.37(7)$ \\
\hline $\mathrm{O}(1)-\mathrm{Dy}(1)-\mathrm{Cl}(1)$ & $101.59(7)$ & $\mathrm{O}(1)-\mathrm{Dy}(1)-\mathrm{Br}(1)$ & $101.24(6)$ \\
\hline $\mathrm{N}(2)-\mathrm{Dy}(1)-\mathrm{N}(2 \mathrm{~A})$ & $69.41(12)$ & $\mathrm{N}(2)-\mathrm{Dy}(1)-\mathrm{N}(2 \mathrm{~A})$ & $69.42(10)$ \\
\hline $\mathrm{N}(1)-\mathrm{Dy}(1)-\mathrm{N}(1 \mathrm{~A})$ & $161.45(12)$ & $\mathrm{N}(1)-\mathrm{Dy}(1)-\mathrm{N}(1 \mathrm{~A})$ & $161.47(11)$ \\
\hline $\mathrm{N}(1)-\mathrm{Dy}(1)-\mathrm{Cl}(1)$ & $80.72(6)$ & $\mathrm{N}(1)-\mathrm{Dy}(1)-\mathrm{Br}(1)$ & $80.73(5)$ \\
\hline $\mathrm{N}(2)-\mathrm{Dy}(1)-\mathrm{Cl}(1)$ & $145.30(6)$ & $\mathrm{N}(2)-\mathrm{Dy}(1)-\operatorname{Br}(1)$ & $145.29(5)$ \\
\hline
\end{tabular}

Symmetry transformations used to generate equivalent atoms: $\mathrm{A}=-x+2, y,-z+3 / 2$

Table S4. The calculated results for Dy ${ }^{\mathrm{III}}$ ions configuration by SHAPE 2.0 software ${ }^{[1]}$ for $\mathbf{1}$ and 2.

\begin{tabular}{lll}
\hline Configuration & $\mathbf{1}$ & $\mathbf{2}$ \\
\hline Heptagon $\left(D_{7 \mathrm{~h}}\right)$ & 34.021 & 34.257 \\
Hexagonal pyramid $\left(C_{6 \mathrm{v}}\right)$ & 23.091 & 23.278 \\
Pentagonal bipyramid $\left(\boldsymbol{D}_{\mathbf{5 h}}\right)$ & $\mathbf{1 . 7 9 6}$ & $\mathbf{2 . 1 4 2}$ \\
Capped octahedron $\left(C_{3 \mathrm{v}}\right)$ & 8.733 & 9.100 \\
Capped trigonal prism $\left(C_{2 \mathrm{v}}\right)$ & 6.964 & 7.273 \\
Johnson pentagonal bipyramid $\mathrm{J} 13\left(D_{5 \mathrm{~h}}\right)$ & 2.184 & 2.288 \\
Johnson elongated triangular pyramid $\mathrm{J} 7\left(C_{3 \mathrm{v}}\right)$ & 21.908 & 22.408 \\
\hline
\end{tabular}


Table S5. The distances $(\AA)$ between neighboring molecules packing along $a, b$ and $c$ directions for $\mathbf{1}$ and $\mathbf{2}$.

\begin{tabular}{lcc}
\hline Direction of Dy $\cdots$ Dy & $\mathbf{1}$ & $\mathbf{2}$ \\
\hline along $\boldsymbol{a}$ direction & 8.667 & 8.672 \\
along $\boldsymbol{b}$ direction & 9.904 & 9.935 \\
along $\boldsymbol{c}$ direction & 8.502 & 8.549 \\
\hline
\end{tabular}

Table S6. Selected bond lengths $(\AA)$ and angles $\left(^{\circ}\right)$ for complexes 1, 2 and Tong's complexes.

\begin{tabular}{llllll}
\hline \multicolumn{1}{c}{$\mathbf{1}$} & \multicolumn{1}{c}{$\mathbf{1}^{\boldsymbol{a}}$} & & \multicolumn{1}{c}{$\mathbf{2}$} & $\mathbf{2}^{\boldsymbol{a}}$ \\
\hline $\mathrm{Dy}(1)-\mathrm{O}(1)$ & $2.160(2)$ & $2.166(4)$ & $\mathrm{Dy}(1)-\mathrm{O}(1)$ & $2.155(2)$ & $2.163(3)$ \\
$\mathrm{Dy}(1)-\mathrm{N}(1)$ & $2.568(3)$ & $2.579(4)$ & $\mathrm{Dy}(1)-\mathrm{N}(1)$ & $2.583(2)$ & $2.594(4)$ \\
$\operatorname{Dy}(1)-\mathrm{N}(2)$ & $2.585(3)$ & $2.587(5)$ & $\mathrm{Dy}(1)-\mathrm{N}(2)$ & $2.578(2)$ & $2.578(4)$ \\
$\operatorname{Dy}(1)-\mathrm{Cl}(1)$ & $2.6680(14)$ & $2.6818(16)$ & $\mathrm{Dy}(1)-\mathrm{Br}(1)$ & $2.8462(6)$ & $2.8515(6)$ \\
$\mathrm{O}(1)-\mathrm{Dy}(1)-\mathrm{O}(1 \mathrm{~A})$ & $156.82(13)$ & $154.3(2)$ & $\mathrm{O}(1)-\mathrm{Dy}(1)-\mathrm{O}(1 \mathrm{~A})$ & $157.52(11)$ & $155.79(18)$ \\
\hline
\end{tabular}

${ }^{a}$ Previous complexes reported by Tong's group, $\mathbf{1}^{\prime}=[\mathrm{Dy}(\mathrm{bbpen}) \mathrm{Cl}], \mathbf{2}^{\prime}=[\mathrm{Dy}(\mathrm{bbpen}) \mathrm{Br}]$. 


\section{Crystal Structure}

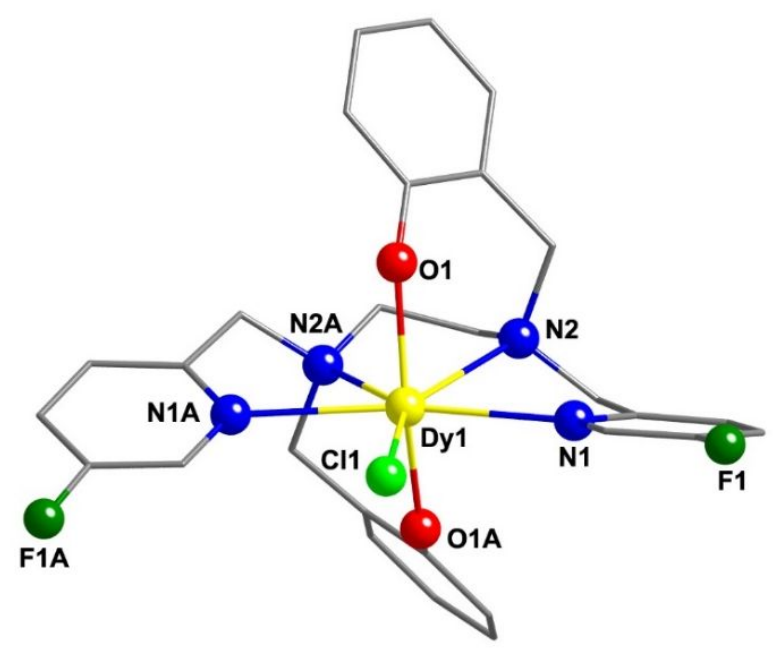

Figure S1. Molecular structure for 1. Hydrogen atoms are omitted for clarity. Color codes: Dy, yellow; $\mathrm{Cl}$, bright green; $\mathrm{O}$, red; $\mathrm{N}$, blue; $\mathrm{C}$, gray. $\mathrm{A}=-x+2, y,-z+3 / 2$.
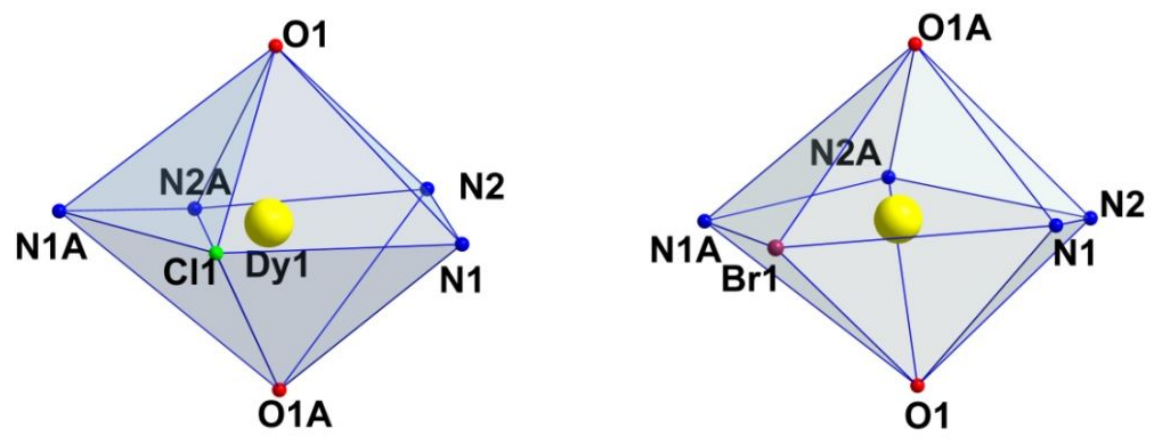

Figure S2. Polyhedrons showing $\mathrm{D}_{5 \mathrm{~h}}$ symmetry around Dy ${ }^{\mathrm{III}}$ ion for $\mathbf{1}$ (left) and $\mathbf{2}$ (right).
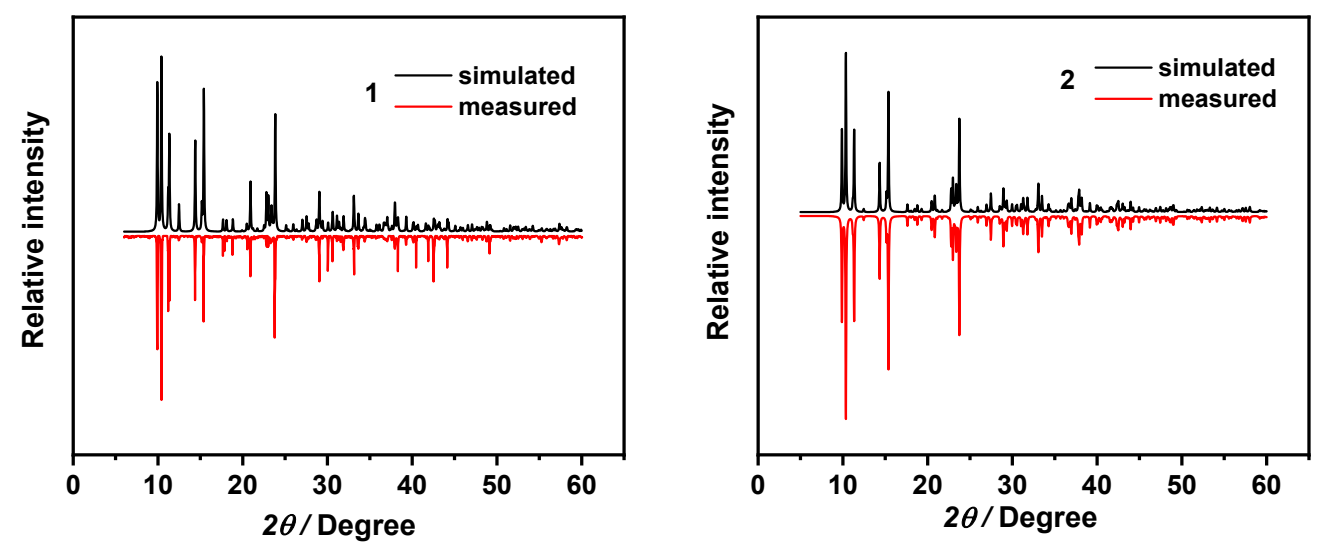

Figure S3. X-ray powder diffraction pattern and simulated PXRD of complexes 1 (left) and 2 (right). 


\section{Magnetic Measurements}
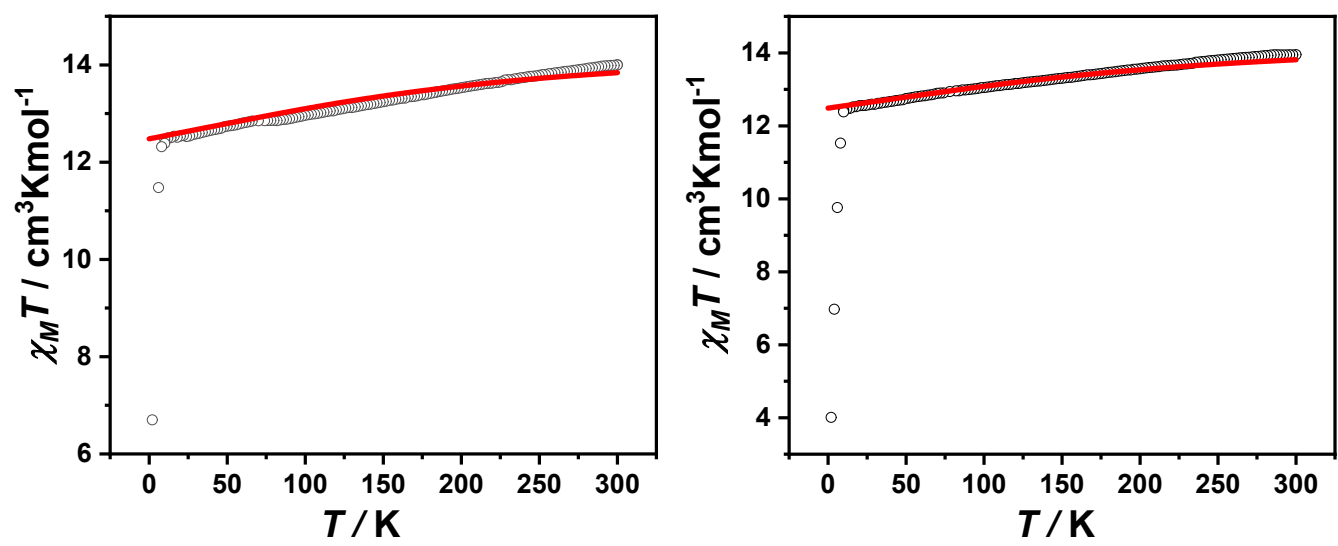

Figure S4. Temperature-dependence of the $\chi_{\mathrm{M}} T$ product under $1 \mathrm{kOe}$ dc field for 1 (left) and 2(right). Solid lines correspond to the ab initio calculation results.
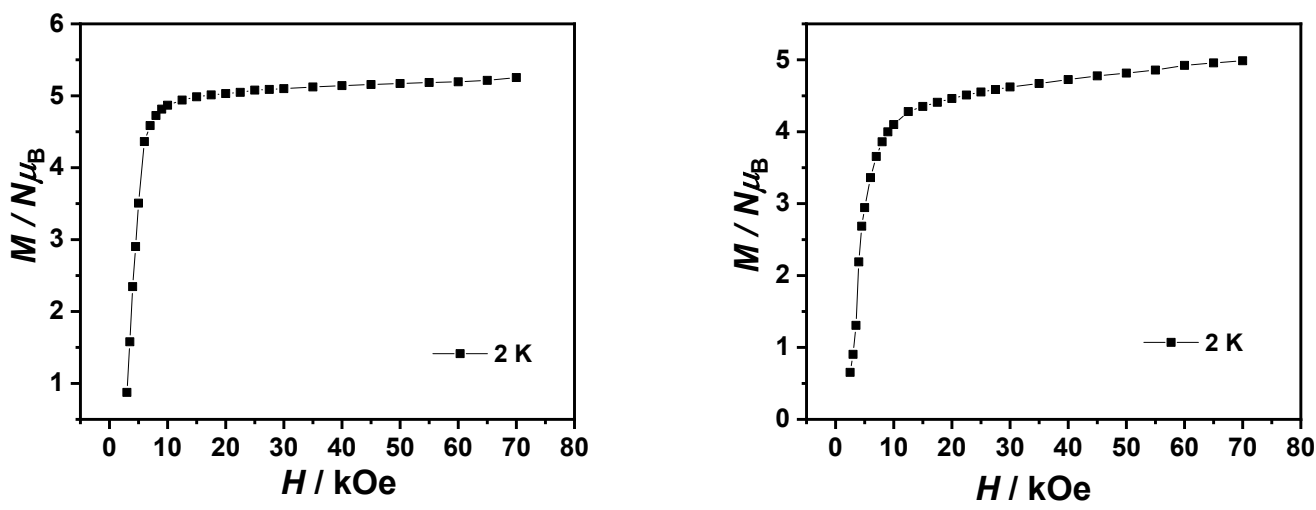

Figure S5. Field dependent magnetization data for complexes 1 (left) and $\mathbf{2}$ (right) at 2 K. Data were collected from 0 to $7 \mathrm{~T}$ in steady fields. 


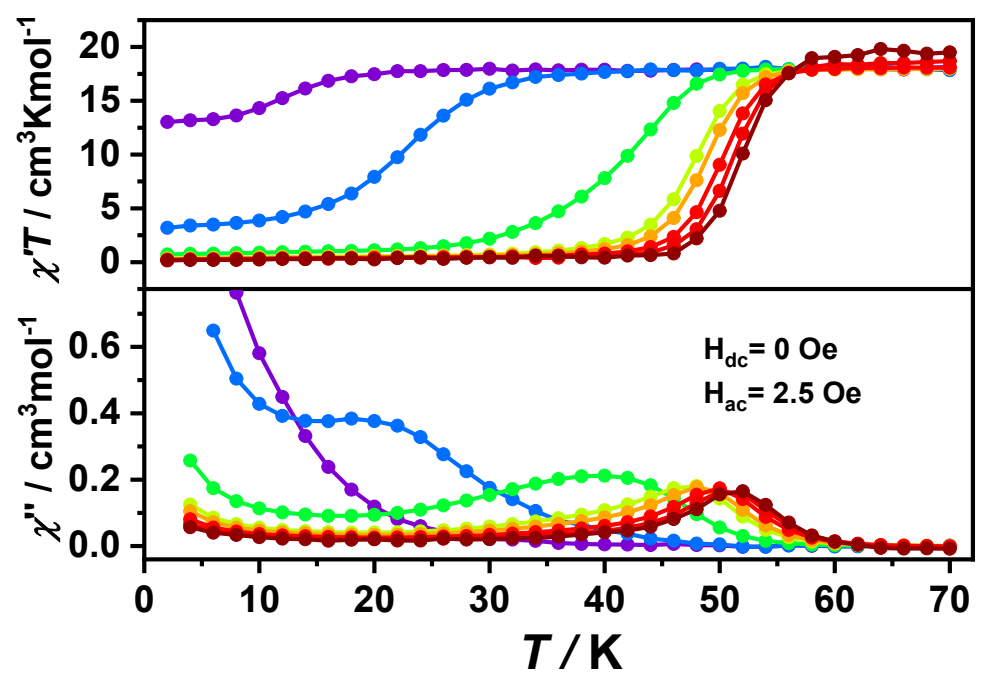

Figure S6. Temperature-dependence of the in-phase $\left(\chi^{\prime}\right)$ and out-of-phase $\left(\chi^{\prime \prime}\right)$ products in zero dc field for complex 1.

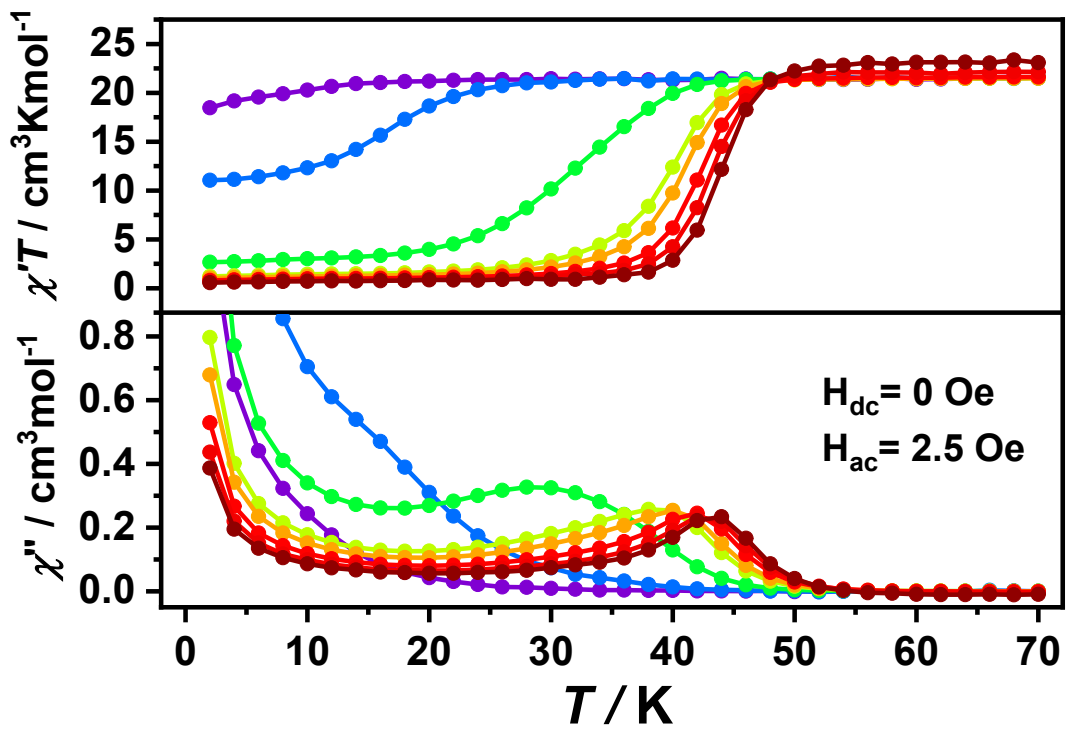

Figure S7. Temperature-dependence of the in-phase $\left(\chi^{\prime}\right)$ and out-of-phase $\left(\chi^{\prime \prime}\right)$ products in zero dc field for complex 2 . 


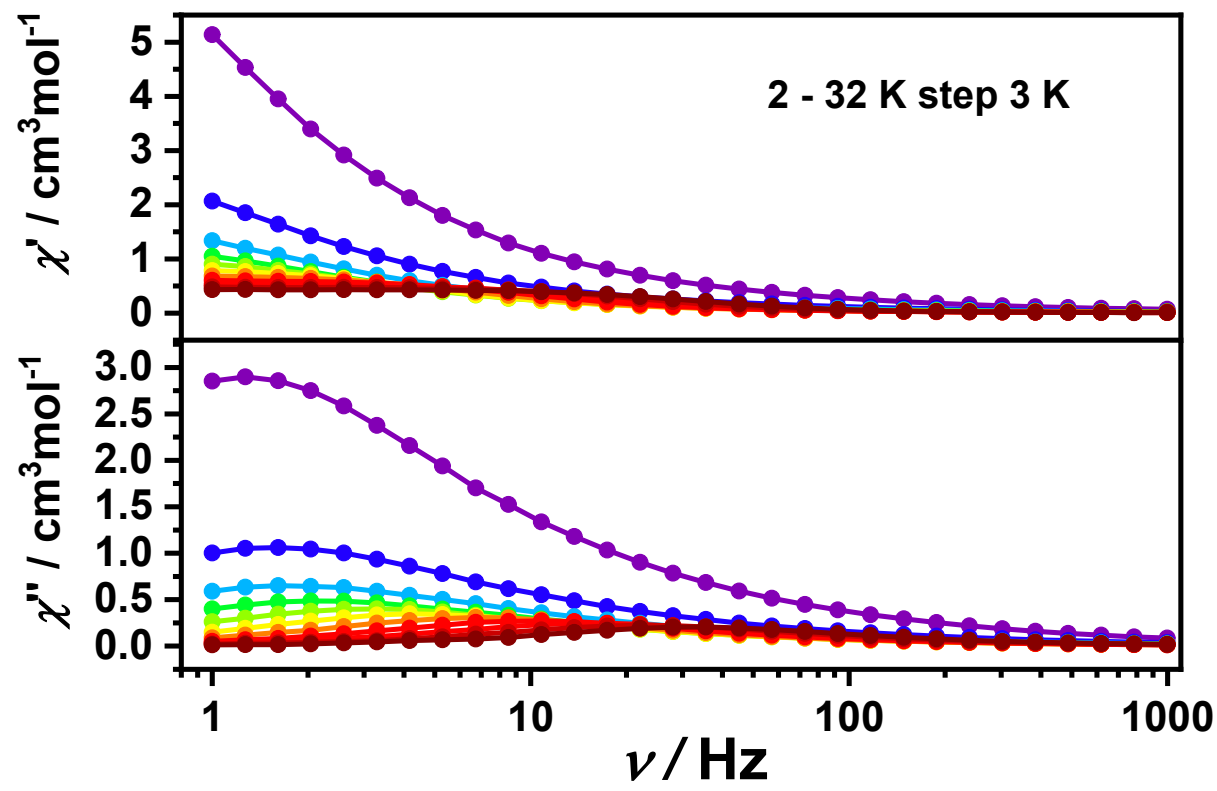

Figure S8. Frequency dependence of in-phase and out-of-phase ac susceptibility for $\mathbf{1}$ in zero applied dc field and at indicated temperatures.

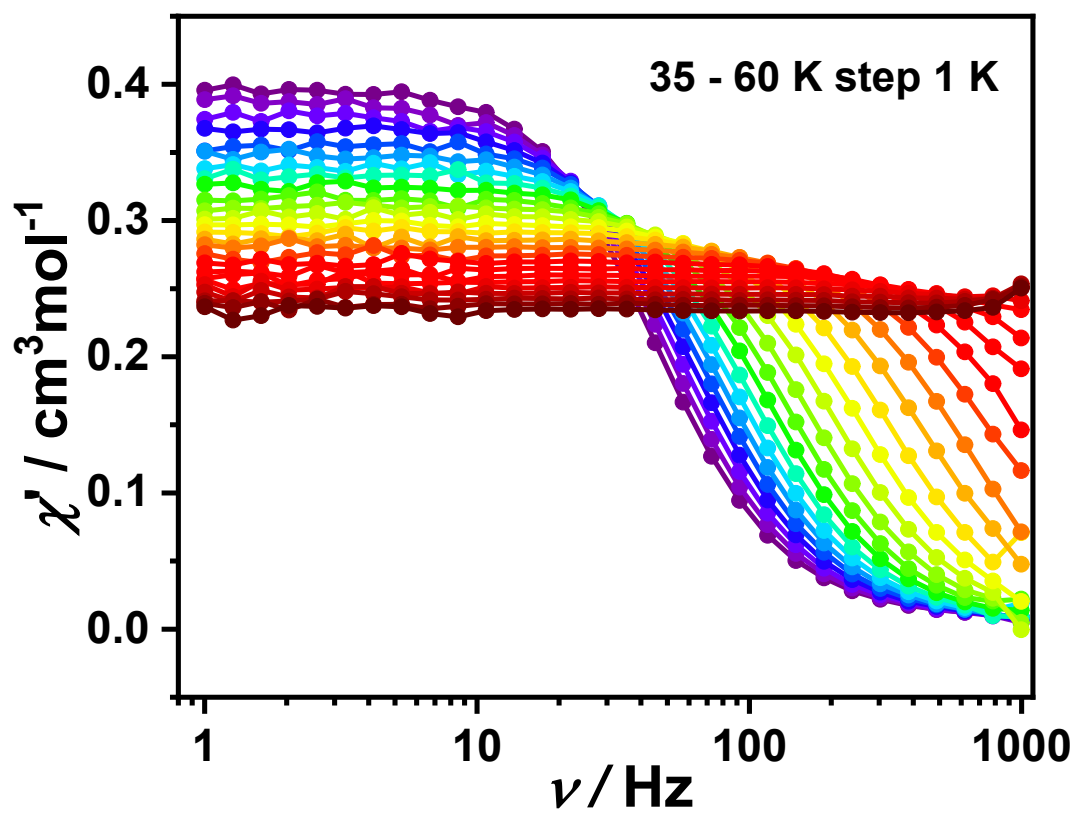

Figure S9. Frequency dependence of in-phase ac susceptibility for $\mathbf{1}$ in zero applied dc field and at indicated temperatures. 


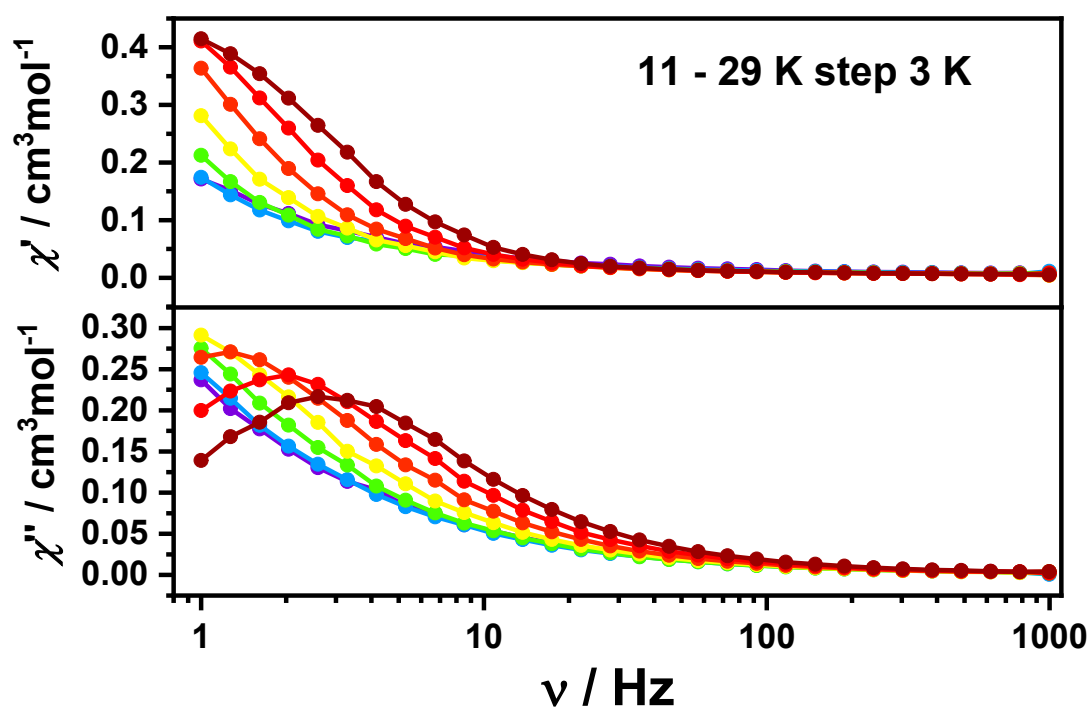

Figure S10. Frequency dependence of in-phase and out-of-phase ac susceptibility for $\mathbf{2}$ in zero applied dc field and at indicated temperatures.

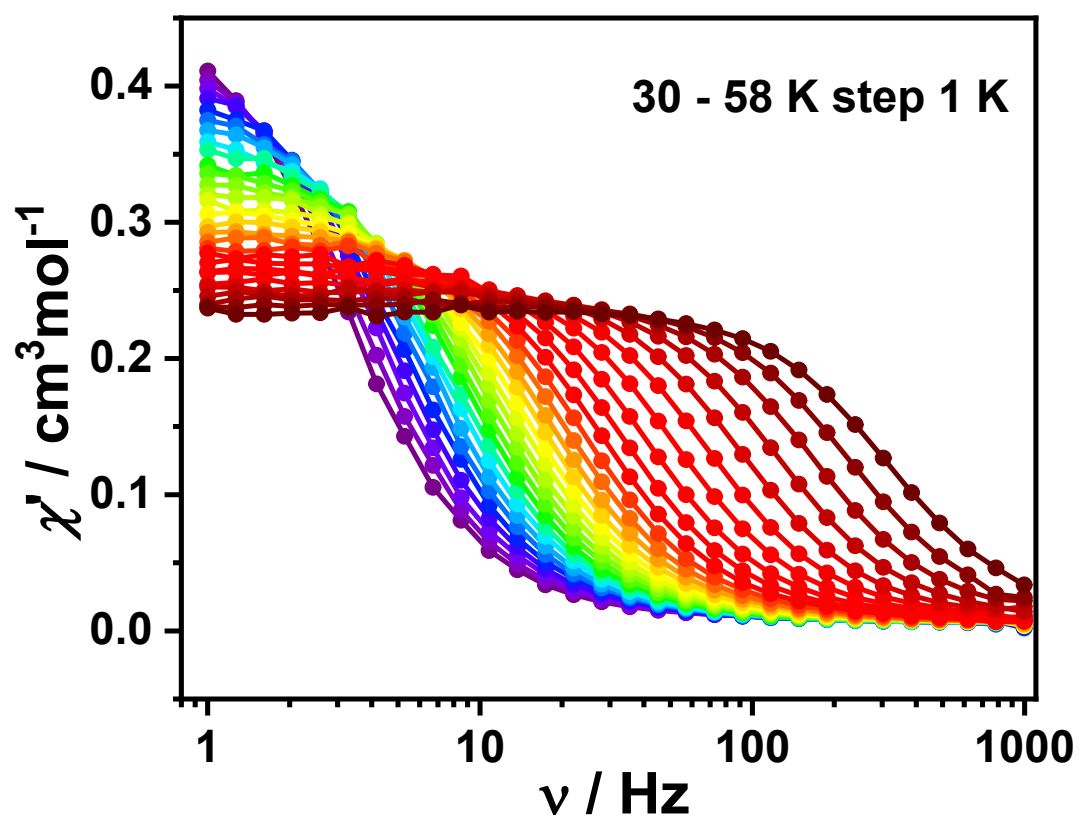

Figure S11. Frequency dependence of in-phase ac susceptibility for $\mathbf{2}$ in zero applied dc field and at indicated temperatures. 


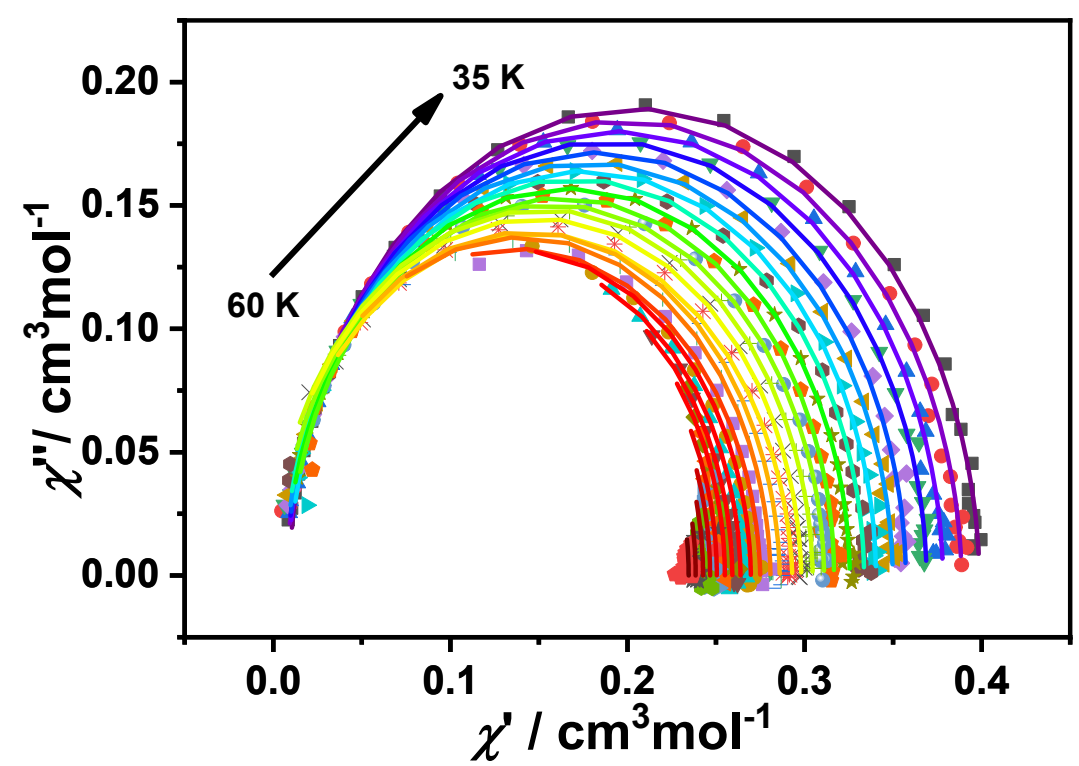

Figure S12. Cole-Cole plots measured at the temperature range of $35-60 \mathrm{~K}$ for 1 . The best fits to the generalized Debye model specified by solid lines $(0.00<\alpha<0.18)$.

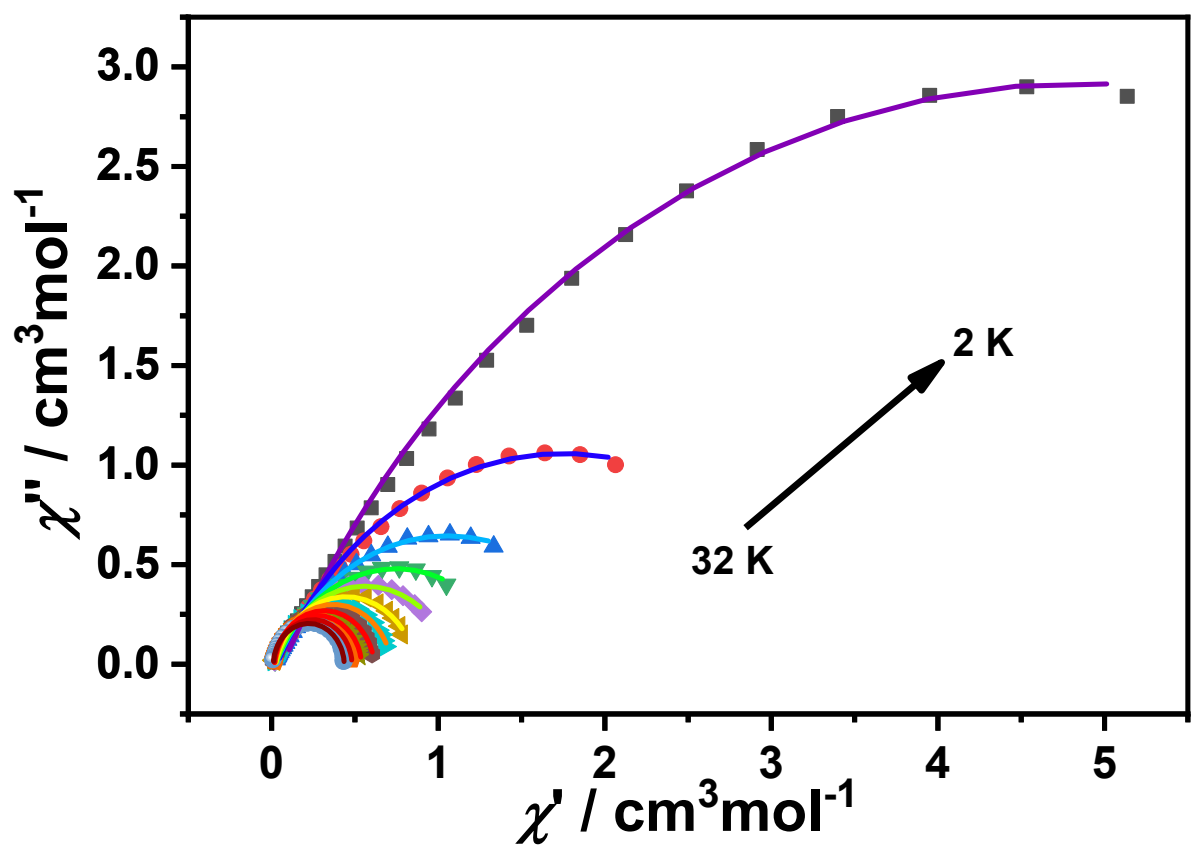

Figure S13. Cole-Cole plots measured at the temperature range of $2-32 \mathrm{~K}$ for 1 . The best fits to the generalized Debye model specified by solid lines $(0.03<\alpha<0.30)$. 


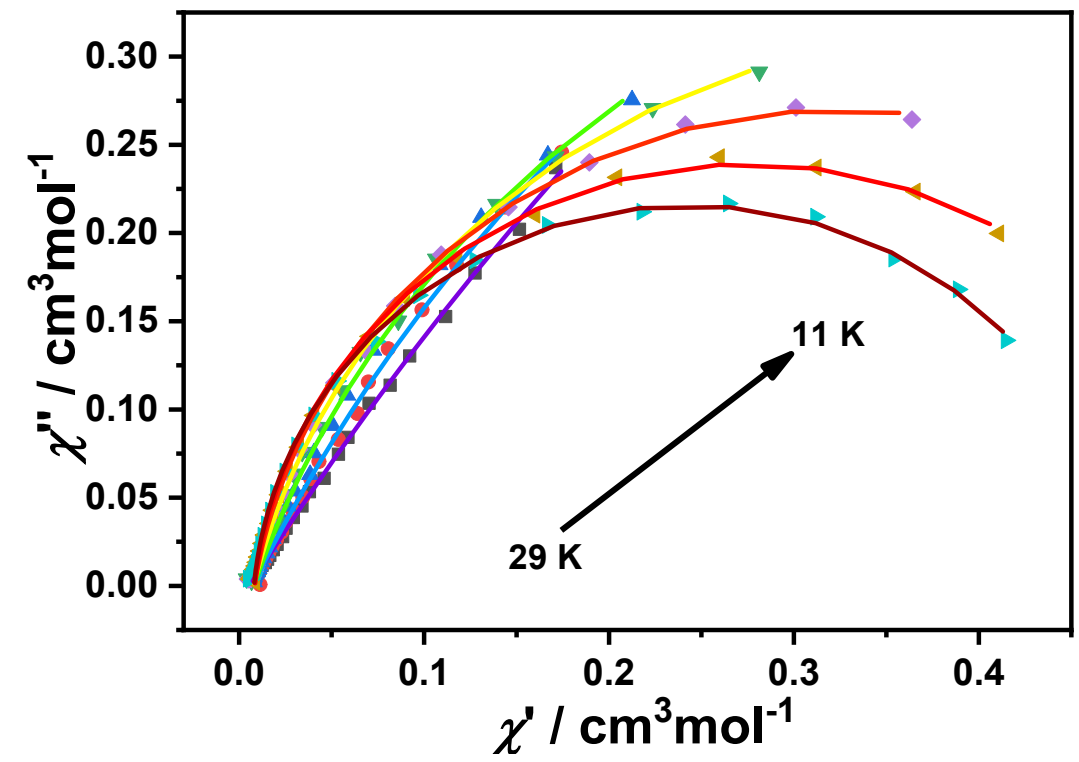

Figure S14. Cole-Cole plots measured at the temperature range of 11-29 K for 2 . The best fits to the generalized Debye model specified by solid lines $(0.06<\alpha<0.34)$.

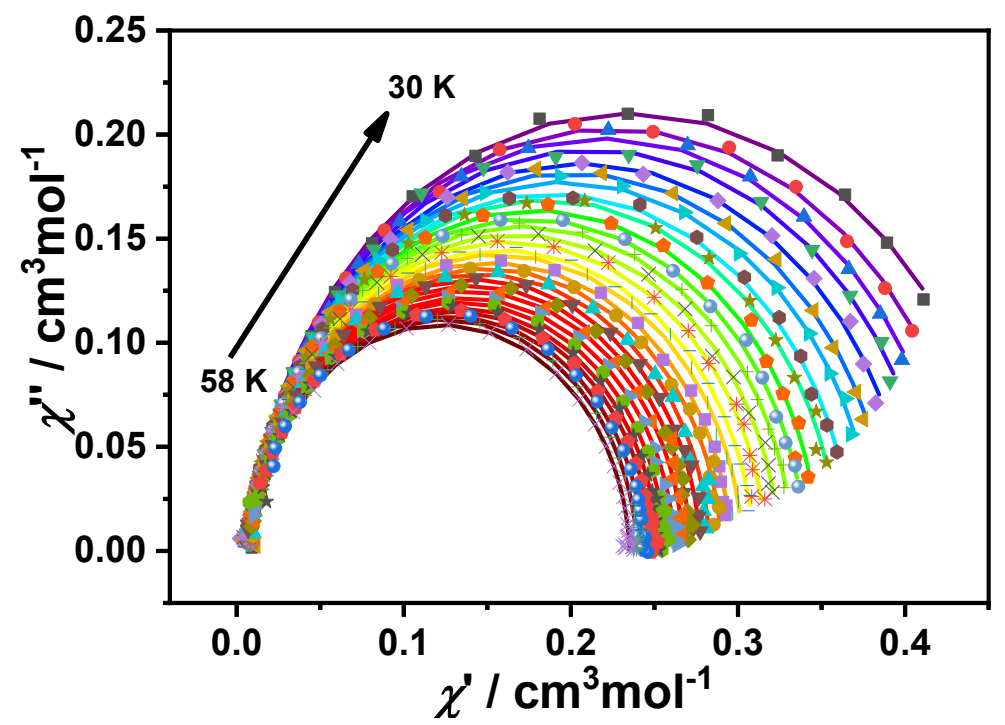

Figure S15. Cole-Cole plots measured at the temperature range of $30-58 \mathrm{~K}$ for 2 . The best fits to the generalized Debye model specified by solid lines $(0.02<\alpha<0.04)$. 
Table S7. Best fit parameters of the generalized Debye model at temperature ranging from 2 to $60 \mathrm{~K}$ under a 0 Oe DC field for $1 . \chi_{\mathrm{T}}$ stands for the isothermal susceptibility, $\chi_{\mathrm{s}}$ for the adiabatic susceptibility, $\tau$ for the relaxation time, and $\alpha$ accounts for the distribution width of the relaxation time.

\begin{tabular}{|c|c|c|c|c|}
\hline & $\chi_{\mathrm{S}} / \mathrm{cm}^{3} \mathrm{~mol}^{-1} \mathrm{~K}$ & $\chi_{\mathrm{T}} / \mathrm{cm}^{3} \mathrm{~mol}^{-1} \mathrm{~K}$ & $\tau / \mathrm{s}$ & $\alpha$ \\
\hline 2 & 0.067786 & 9.642890 & 0.148476 & 0.303225 \\
\hline 5 & 0.032499 & 3.475330 & 0.115129 & 0.298349 \\
\hline 8 & 0.024362 & 2.088060 & 0.097622 & 0.288750 \\
\hline 11 & 0.023363 & 1.468940 & 0.074181 & 0.254114 \\
\hline 14 & 0.024814 & 1.100630 & 0.049143 & 0.198513 \\
\hline 17 & 0.023289 & 0.869386 & 0.032319 & 0.139995 \\
\hline 20 & 0.020308 & 0.721346 & 0.021654 & 0.098589 \\
\hline 23 & 0.017292 & 0.616739 & 0.014357 & 0.068054 \\
\hline 26 & 0.014295 & 0.540699 & 0.009659 & 0.047892 \\
\hline 29 & 0.013771 & 0.482935 & 0.006679 & 0.030947 \\
\hline 32 & 0.010540 & 0.435854 & 0.004665 & 0.023049 \\
\hline 35 & 0.009018 & 0.398746 & 0.003378 & 0.018505 \\
\hline 36 & 0.007541 & 0.388742 & 0.003043 & 0.021223 \\
\hline 37 & 0.008162 & 0.378185 & 0.002746 & 0.017181 \\
\hline 38 & 0.007477 & 0.368956 & 0.002473 & 0.017148 \\
\hline 39 & 0.007731 & 0.357223 & 0.002208 & 0.011880 \\
\hline 40 & 0.006629 & 0.349877 & 0.001979 & 0.016056 \\
\hline 41 & 0.009572 & 0.340293 & 0.001769 & 0.005242 \\
\hline 42 & 0.006287 & 0.333678 & 0.001544 & 0.011546 \\
\hline 43 & 0.007420 & 0.325565 & 0.001345 & 0.008711 \\
\hline 44 & 0.009227 & 0.316659 & 0.001151 & 0.002096 \\
\hline 45 & 0.003379 & 0.311077 & 0.000945 & 0.014079 \\
\hline 46 & 0.000000 & 0.304616 & 0.000761 & 0.016819 \\
\hline 47 & 0.000000 & 0.298174 & 0.000608 & 0.018697 \\
\hline 48 & 0.000000 & 0.293102 & 0.000466 & 0.034006 \\
\hline 49 & 0.000000 & 0.286008 & 0.000358 & 0.016786 \\
\hline 50 & 0.000000 & 0.280770 & 0.000269 & 0.014851 \\
\hline 51 & 0.000000 & 0.275003 & 0.000194 & 0.023909 \\
\hline 52 & 0.000000 & 0.269687 & 0.000144 & 0.013956 \\
\hline
\end{tabular}




\begin{tabular}{lllll}
53 & 0.000000 & 0.263876 & 0.000102 & 0.013605 \\
54 & 0.000000 & 0.259232 & 0.000075 & 0.009585 \\
55 & 0.000000 & 0.255016 & 0.000054 & 0.003171 \\
56 & 0.000000 & 0.250473 & 0.000040 & 0.000000 \\
57 & 0.000000 & 0.246653 & 0.000028 & 0.000000 \\
58 & 0.000000 & 0.242691 & 0.000020 & 0.000000 \\
59 & 0.000000 & 0.238544 & 0.000014 & 0.000000 \\
60 & 0.000000 & 0.234569 & 0.000010 & 0.000000 \\
\hline
\end{tabular}

Table S8. Best fit parameters of the generalized Debye model at temperature ranging from 11 to $58 \mathrm{~K}$ under a 0 Oe DC field for 2. $\chi_{\mathrm{T}}$ stands for the isothermal susceptibility, $\chi_{\mathrm{s}}$ for the adiabatic susceptibility, $\tau$ for the relaxation time, and $\alpha$ accounts for the distribution width of the relaxation time.

\begin{tabular}{ccccc}
\hline Temperature $/ \mathrm{K}$ & $\chi_{\mathrm{S}} / \mathrm{cm}^{3} \mathrm{~mol}^{-1} \mathrm{~K}$ & $\chi_{\mathrm{T}} / \mathrm{cm}^{3} \mathrm{~mol}^{-1} \mathrm{~K}$ & $\tau / \mathrm{s}$ & $\alpha$ \\
\hline 11 & 0.005637 & 3.140900 & 5.616030 & 0.345864 \\
14 & 0.007261 & 1.760310 & 1.665810 & 0.278712 \\
17 & 0.007999 & 1.067150 & 0.542105 & 0.202502 \\
20 & 0.007802 & 0.801606 & 0.259809 & 0.150383 \\
23 & 0.008196 & 0.640456 & 0.139229 & 0.100529 \\
26 & 0.008480 & 0.541979 & 0.083728 & 0.069425 \\
29 & 0.008046 & 0.479034 & 0.055308 & 0.055869 \\
30 & 0.008320 & 0.460002 & 0.048437 & 0.045546 \\
31 & 0.008260 & 0.440681 & 0.042285 & 0.040460 \\
32 & 0.007984 & 0.428160 & 0.037490 & 0.037270 \\
33 & 0.007766 & 0.417285 & 0.033668 & 0.038156 \\
34 & 0.007202 & 0.404512 & 0.030020 & 0.041191 \\
35 & 0.007665 & 0.391475 & 0.026817 & 0.035153 \\
36 & 0.007394 & 0.381569 & 0.024203 & 0.034554 \\
37 & 0.007342 & 0.368418 & 0.021619 & 0.031962 \\
38 & 0.007809 & 0.359926 & 0.019673 & 0.027380 \\
39 & 0.007894 & 0.348302 & 0.017743 & 0.024757 \\
40 & 0.007689 & 0.340532 & 0.016143 & 0.026764 \\
41 & 0.007621 & 0.332812 & 0.014655 & 0.026122 \\
& & & & \\
\hline 36 & 0 & 0 &
\end{tabular}




\begin{tabular}{lllll}
42 & 0.007368 & 0.324801 & 0.013286 & 0.027066 \\
43 & 0.007686 & 0.316780 & 0.012051 & 0.024931 \\
44 & 0.007116 & 0.309680 & 0.010904 & 0.029040 \\
45 & 0.007973 & 0.302742 & 0.009766 & 0.021824 \\
46 & 0.007604 & 0.295993 & 0.008706 & 0.025041 \\
47 & 0.008178 & 0.290119 & 0.007682 & 0.023588 \\
48 & 0.008582 & 0.283021 & 0.006618 & 0.019299 \\
50 & 0.008548 & 0.277269 & 0.005623 & 0.018810 \\
51 & 0.009296 & 0.271774 & 0.004678 & 0.018333 \\
52 & 0.009525 & 0.267112 & 0.003811 & 0.019257 \\
53 & 0.009364 & 0.262087 & 0.003003 & 0.023321 \\
54 & 0.009415 & 0.256324 & 0.002293 & 0.019750 \\
55 & 0.010913 & 0.251848 & 0.001748 & 0.018766 \\
56 & 0.009941 & 0.248313 & 0.001296 & 0.021251 \\
57 & 0.011024 & 0.243157 & 0.000953 & 0.017414 \\
58 & 0.008479 & 0.239620 & 0.000691 & 0.024751 \\
\hline
\end{tabular}




\section{Theory Calculations}

\section{Theoretical methods and computational details}

Multiconfigurational $a b$ initio calculations, including spin-orbit coupling (SOC), were performed on the experimental structures of the complexes in this work to explore their SMM properties. This type of calculation includes two steps: ${ }^{[2]} 1$ ) a set of spin eigenstates are obtained by the state-averaged (SA) CASSCF method; ${ }^{3]}$ 2) the low-lying SOC states, i.e., Kramers doublets (KD) herein, are obtained by state interaction which is the diagonalization of the SOC matrix in the space spanned by the spin eigenstates from the first step. All the calculations were carried out with the MOLCAS@UU, a version of MOLCAS 8.0 ${ }^{[4,5]}$ which is freely distributed for academic users.

In the CASSCF step, the active space consisted of 9 electrons in 7 orbitals and a total number of 21 sextets were included. Due to the hardware limitation, other highly excited spin states were not considered. The step of state interaction were performed by the RASSI-SO module $^{[6]}$ with the SOC integrals from the AMFI method. ${ }^{[7]}$ The ANO-RCC basis sets, ${ }^{[8-10]}$ including VTZP for Dy, VDZ for C and $\mathrm{H}$ as well as VDZP for other atoms, were used. The SINGLE_ANISO module ${ }^{[11,12]}$, developed by Chibotaru et al, was used to obtain the $g$-tensors, transition magnetic moments and other parameters characterizing the magnetic anisotropy.

\section{Theoretical analysis}

The microscopic reason for the SMM behavior is the fact that the magnetic relaxation [13] of the system is slow enough to be observed in experiment [14-19]. Clearly, the necessary condition for the SMM properties is that the relaxation rate $\tau^{-1[20]}$ is low enough or, equally, the relaxation time $\tau$ is long enough.

Being different from early SMMs based on polynuclear transition metal complexes, the magnetic relaxation of Ln-SIM is usually a collective result of several constituent pathways [1417,21] including the spin-phonon ones ${ }^{[22]}$ and quantum tunneling of magnetization (QTM) simultaneously. ${ }^{[23]}$ QTM rate $\left(\tau_{\mathrm{QTM}}^{-1}\right)$ is widely accepted to be temperature independent ${ }^{[23]}$ while the rate of spin-phonon ones increases with temperature ${ }^{[15-17,22]}$. Therefore, $\tau_{\mathrm{QTM}}^{-1}$ dominates the total relaxation rate in low temperature region and, for the whole temperature region, the lower limit of $\tau^{-1}$ is just $\tau_{\mathrm{QTM} \cdot}^{-1}{ }^{[19]}$

It needs to clarify that QTM itself is not enough to provide an overall description of the magnetic relaxation due to the dominance of spin-phonon pathways in higher temperature regime ${ }^{[15-17,22]}$. Unfortunately, accurate description on spin-phonon pathways is difficult since it needs the calculation of both the phonon spectrum and spin-phonon coupling [24-28]. 
However, there is one parameter $U_{\text {eff }}$, i.e., the effective magnetic reversal barrier, which has been widely utilized to characterize the rate of spin- phonon relaxation. Generally, higher value of $U_{\text {eff }}$ is assumed to be related to lower spin-phonon relaxation rate. Therefore the criterion of good candidate of high-performance SMM could be concisely described as the simultaneous achievement of both long $\tau_{\mathrm{QTM}}$ and high $U_{\text {eff }}{ }^{[19]}$.

Microscopically, QTM is driven by the so-called tunnel splitting $\left(\Delta_{\text {tun }}\right)$ arising from some kind of interaction which leads to the mixture of the two degenerate states of opposite directions of magnetization. ${ }^{[15,19,23]}$ For Kramers systems here, $\Delta_{\text {tun }}$ could only arise from Zeeman interaction (eqn S1a) between the magnetic moment of the system $(\vec{\mu})$ and the existing magnetic field $(\vec{B}) \cdot{ }^{[14-16,19]}$

$$
\begin{aligned}
\widehat{H}_{Z e e} & =-\vec{B} \cdot \widehat{\vec{\mu}} \\
\widehat{H}_{Z e e} & =\beta \sum_{\alpha} B_{\alpha} g_{\alpha} \widetilde{S}_{\alpha} \quad \alpha=X, Y, Z
\end{aligned}
$$

For Kramers systems, the electronic states could be grouped into various degenerate doublets called Kramers doublet (KD). Each KD could be associated with a pseudospin of 1/2 $(\tilde{S}=1 / 2)$ in a unique way. ${ }^{[11,12,14,29]}$ Thus Zeeman interaction within the ground $\mathrm{KD}| \pm 1 / 2\rangle$, which is responsible for the QTM of Kramers SIM, could be reformulated into eqn S1b ${ }^{[29]}$ under the principal directions of the $g$-matrix of $1 / 2 \tilde{S}$. The analysis of Kramers SIMs, based on these $\mathrm{g}$ values, is reliable and has been widely accepted. ${ }^{[2,11,12,14-18,30,31]}$ Based on eqn $\mathrm{S} 1 \mathrm{~b}$, both $\Delta_{\text {tun }}$ and energy bias $\left(\varepsilon_{\text {bias }}\right)$ are determined by eqns $\mathrm{S} 2 \mathrm{a}$ and $\mathrm{S} 2 \mathrm{~b}$ respectively.

$$
\begin{aligned}
\Delta_{\text {tun }} & =\frac{1}{2}\left[\beta\left(g_{\mathrm{X}}^{2} B_{\mathrm{X}}^{2}+g_{\mathrm{Y}}^{2} B_{\mathrm{Y}}^{2}\right)^{1 / 2}\right] \\
\varepsilon_{\text {bias }} & =\beta B_{\mathrm{Z}} g_{\mathrm{Z}}
\end{aligned}
$$

Knowing the value of $\Delta_{\text {tun }}$ and $\varepsilon_{\text {bias }}, \tau_{\text {QTM }}^{-1}$ could be predicted according to a general equation (eqn S3a). ${ }^{[19]}$ A further assumption of isotropic $\vec{B}$ leads to eqn $\mathrm{S} 3 \mathrm{~b}$, which is easier to use. ${ }^{[19]}$ Finally, $\tau_{\mathrm{QTM}}$ is reciprocal to, $\tau_{\mathrm{QTM}}^{-1}$ as shown in eqn $\mathrm{S} 3 \mathrm{~d}$. The application of eqn $\mathrm{S} 3 \mathrm{~b}$ needs the magnitude of $\vec{B}$ ( $B_{\text {ave }}$ ) which can not be provided by ab initio calculations directly.

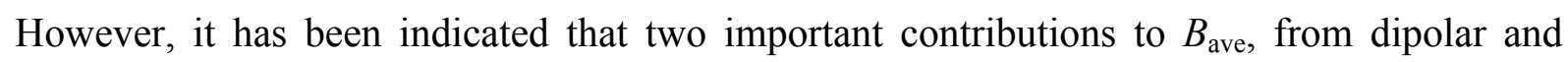
hyperfine interactions, are both of a few tens of mini-tesla (mT). ${ }^{[23]}$ Thus $B_{\text {ave }}$ could be taken as an adjustable parameter and $20 \mathrm{mT}$ is a reasonable selection according to our previous comparison between theoretical and experimental results ${ }^{[19]}$. It ought to be stated that, due to the usage of an adjustable parameter, the accuracy of the theoretical predictions from eqn S3b should be limited to order of magnitude. ${ }^{[19]}$ 


$$
\begin{aligned}
\tau_{\mathrm{QTM}}^{-1} & =\frac{2}{h} \cdot \frac{\Delta_{\text {tun }}^{2}}{\left(\varepsilon_{\text {bias }}^{2}+4 \Delta_{\text {tun }}^{2}\right)^{\frac{1}{2}}} \\
\tau_{\mathrm{QTM}}^{-1} & =\frac{\beta B_{\text {ave }}}{h} \cdot \frac{g_{\mathrm{XY}}^{2}}{2\left(g_{\mathrm{XY}}^{2}+g_{\mathrm{Z}}^{2}\right)^{\frac{1}{2}}} \\
g_{\mathrm{XY}} & =\left(g_{\mathrm{X}}^{2}+g_{\mathrm{Y}}^{2}\right)^{\frac{1}{2}} \\
\tau_{\mathrm{QTM}} & =\frac{1}{2 \tau_{\mathrm{QTM}}^{-1}}
\end{aligned}
$$

For 1 , with $B_{\text {ave }}$ set to be $20 \mathrm{mT}$, theoretical $\tau_{\mathrm{QTM}}$ and experimental fitted value are nearly within one order of magnitude (Table S9). Since the accuracy of eqn S3b is at the level of order of magnitude, the selection of $20 \mathrm{mT}$ of $B_{\text {ave }}$ ought to be reasonable for the compounds here. As shown in Table S9, $\tau_{\mathrm{QTM}}$ of $\mathbf{2}$ is as large as 6 times of that of $\mathbf{1}$. Thus the ground state QTM of $\mathbf{2}$ is remarkably weaker than that of $\mathbf{1}$, so that, better SMM property should be expected for 2 according to these theoretical predictions. This is indeed consistent to experimental observations.

In the comparison between $\mathbf{2}$ and 2', their $\tau_{\mathrm{QTM}}$ are actually close to each other, $0.075 \mathrm{~s}(2)$ vs $0.109 \mathrm{~s}$ (2'). Due to the quite close strengths of QTM of $\mathbf{2}$ and 2', spin-phonon relaxation, which could be characterized by $U_{\text {eff, }}$ should be the main origin of their different SMM properties, e.g., different hysteresis temperatures. Similar results exist in the comparison between $\mathbf{1}$ and $\mathbf{1}$ 'as shown in Table S9.

It is well accepted that $U_{\text {eff }}$ is closely related to crystal field (CF) splitting. As shown in Table S9, the complexes here do have larger CF splitting when compared to Tong's structures, e.g., $412.4 \mathrm{~cm}^{-1}\left(\mathrm{KD}_{1}\right.$ of 2$)$ vs $392.2 \mathrm{~cm}^{-1}\left(\mathrm{KD}_{1}\right.$ of $\left.\mathbf{2}^{\prime}\right)$. With reliable prediction of $\tau_{\mathrm{QTM}}^{-1}$ of various $\mathrm{KDs}, U_{\text {eff }}$ could be theoretically predicted within the framework of thermally-assisted QTM, i.e., TA-QTM. ${ }^{[19,32-34]}$ The $U_{\text {eff }}$ from both theoretical prediction and experimental fitting are shown in Table S10. Clearly, both theoretical and experimental values support the increase of $U_{\text {eff }}$ of the compounds here by around $100 \mathrm{~K}$ when compared to the corresponding ones in previous work of Tong's group. ${ }^{[32]}$

As shown in eqn $\mathrm{S} 3 \mathrm{~b}$, under the assumption of same $B_{\text {ave, }}$, the difference in the QTM of Kramers SIM mainly arises from the value of $g_{\mathrm{XY}}$ since $g_{\mathrm{Z}}$ is usually quite close to 20 . The $g_{\mathrm{XY}}$ value is determined by the electronic structure of $\mathrm{KD}$ and, clearly, small $g_{\mathrm{XY}}$ is desired. For SIM based on $\mathrm{Dy}^{3+}$ ion, the ideal electronic structure of the ground $\mathrm{KD}$ arises from that the contribution from the $| \pm 15 / 2\rangle$ components of ground ${ }^{6} H_{15 / 2}$ multiplet of $\mathrm{Dy}^{3+}$ ion is $100 \%{ }^{[15,16,18,31]}$ 
Due to the oblate electron density of the ground multiplet of $\mathrm{Dy}^{3+}$ ion, ${ }^{[35,36]}$ the suitable electronic structure of Dy-SIM could be approached via that the electrostatic repulsion by the axial ligating atoms should exceed that by the equatorial atoms as much as possible. ${ }^{[18,37-39]}$

For the compounds here of PBP coordination geometry, within the first sphere, two $\mathrm{O}$ atoms are at the axial positions and the equatorial positions are occupied by four $\mathrm{N}$ atoms and one $\mathrm{Cl}$ or $\mathrm{Br}$ atom. With the ab initio LoProp charges and the lengths to central $\mathrm{Dy}^{3+}$ of the atoms in the first sphere (Table S11), both the axial electrostatic potential, indicated as ESP(ax), and equatorial electrostatic potential, i.e., ESP(equ), could be approximated by the sum of related atomic contributions.

Based on the analysis above, the smaller the $\operatorname{ESP}(\mathrm{equ}) / \operatorname{ESP}(\mathrm{ax})$ ratio is, the better the fulfillment of condition for high performance Dy-SIM is. As shown in Table S12, 2 of the highest hysteresis temperature does have the smallest value of the $\operatorname{ESP}(\mathrm{equ}) / \operatorname{ESP}(\mathrm{ax})$ ratio. In comparison to the corresponding ones in previous work of Tong's group, [32] the $\mathrm{ESP}(\mathrm{equ}) / \mathrm{ESP}(\mathrm{ax})$ ratios of the compounds here are indeed smaller, e.g., 0.824 (1) vs 0.843 (1') and $0.778(\mathbf{2})$ vs $0.807\left(\mathbf{2}^{\prime}\right)$.

The decreases of the ESP(equ)/ESP(ax) ratios of the compounds here arise mainly from the decreases of the equatorial ESP by 0.010 (1) and 0.016 a.u. (2). Clearly the smaller magnitudes of equatorial ESP come from the reduced magnitude of negative charges of the equatorial $\mathrm{N}$ atoms (Table S11), resulted from the introduction of electron-withdrawing $\mathrm{F}$ atom to the equatorial pyridyl groups. However, it needs to indicate that the modification on equatorial ligands also leads to certain degree of increase of axial ESP of the compounds here, e.g., 0.007 a.u. in 1 and 0.010 a.u. in 2. As shown in Table S11, the Dy-O $a x$ lengths of the compounds here are slightly shorter than those of the corresponding ones in previous work of Tong's group. This might be the reason for the increased axial ESP.

It needs to be mentioned that the electrostatic analysis above is preliminary and it might be too simple since the importance of covalency in the crystal field felt by central $\mathrm{Ln}^{3+}$ ion have been indicated recently. ${ }^{[40]}$ For $\mathrm{Dy}^{3+}$ ion, the leading axial crystal field parameters (CFP) is the $B(2,0)$ term and $B(2,2)$ is usually the leading transversal term. ${ }^{[14,16,31,40]}$ From a perturbative viewpoint, axial CFPs produce the ideal electronic structure which is further lowered by the perturbation of transversal CFP. ${ }^{[14,16,40]}$ Thus the ratio $\left|\frac{B(2,2)}{B(2,0)}\right|$ might be capable of characterizing the system in the sense that lower value of $\left|\frac{B(2,2)}{B(2,0)}\right|$ leads to smaller value of 
$g_{\mathrm{XY}} \cdot{ }^{[41]}$ As shown in Table $\mathrm{S} 12$, the result of $\left|\frac{B(2,2)}{B(2,0)}\right|$ is generally consistent to that of ESP analysis above.

Table S9 Ab initio computed relative energies (in $\mathrm{cm}^{-1}$ ) and principal values of the $g$-tensors of the lowest KDs as well as theoretical and experimental values of $\tau_{\mathrm{QTM}}$ (in s)

\begin{tabular}{|c|c|c|c|c|c|}
\hline & & 1 & 2 & $2^{\prime a}$ & $1^{\prime a}$ \\
\hline \multirow[t]{6}{*}{$\overline{\mathrm{KD}_{0}}$} & $E$ & 0.000 & 0.000 & 0.000 & 0.000 \\
\hline & $\mathrm{g}_{Z}$ & 19.9797 & 19.9851 & 19.9843 & 19.9786 \\
\hline & $\mathrm{g}_{X}$ & $0.1397 \times 10^{-02}$ & $0.6128 \times 10^{-03}$ & $0.5198 \times 10^{-03}$ & $0.1233 \times 10^{-02}$ \\
\hline & $\mathrm{g}_{Y}$ & $0.1867 \times 10^{-02}$ & $0.7627 \times 10^{-03}$ & $0.6210 \times 10^{-03}$ & $0.1598 \times 10^{-02}$ \\
\hline & $\mathrm{g}_{X Y}$ & $0.2332 \times 10^{-02}$ & $0.9783 \times 10^{-03}$ & $0.8098 \times 10^{-03}$ & $0.2018 \times 10^{-02}$ \\
\hline & $\tau_{\mathrm{QTM}}$ & $0.013(0.16)^{b}$ & 0.075 & 0.109 & 0.018 \\
\hline \multirow[t]{5}{*}{$\mathrm{KD}_{1}$} & $\mathrm{E}$ & 395.215 & 412.364 & 392.158 & 373.442 \\
\hline & $\mathrm{g}_{Z}$ & 16.9525 & 17.0299 & 17.0360 & 16.9493 \\
\hline & $\mathrm{g}_{X}$ & $0.1400 \times 10^{+00}$ & $0.7268 \times 10^{-01}$ & $0.7155 \times 10^{-01}$ & $0.1325 \times 10^{+00}$ \\
\hline & $\mathrm{g}_{Y}$ & $0.2060 \times 10^{+00}$ & $0.9148 \times 10^{-01}$ & $0.8975 \times 10^{-01}$ & $0.1991 \times 10^{+00}$ \\
\hline & $\mathrm{g}_{X Y}$ & $0.2490 \times 10^{+00}$ & $0.1168 \times 10^{+00}$ & $0.1148 \times 10^{+00}$ & $0.2392 \times 10^{+00}$ \\
\hline \multirow[t]{5}{*}{$\mathrm{KD}_{2}$} & $\mathrm{E}$ & 610.730 & 667.082 & 625.447 & 565.584 \\
\hline & $\mathrm{g}_{Z}$ & 2.6190 & 13.4227 & 13.5082 & 10.7731 \\
\hline & $\mathrm{g}_{X}$ & $0.1047 \times 10^{+02}$ & $0.9951 \times 10^{+00}$ & $0.8671 \times 10^{+00}$ & $0.2563 \times 10^{+01}$ \\
\hline & $\mathrm{g}_{Y}$ & $0.6886 \times 10^{+01}$ & $0.1821 \times 10^{+01}$ & $0.1589 \times 10^{+01}$ & $0.6494 \times 10^{+01}$ \\
\hline & $\mathrm{g}_{X Y}$ & $0.1253 \times 10^{+02}$ & $0.2075 \times 10^{+01}$ & $0.1811 \times 10^{+01}$ & $0.6982 \times 10^{+01}$ \\
\hline \multirow[t]{5}{*}{$\mathrm{KD}_{3}$} & $\mathrm{E}$ & 684.751 & 769.646 & 717.703 & 631.544 \\
\hline & $\mathrm{g}_{Z}$ & 0.3499 & 10.5817 & 9.6961 & 1.5887 \\
\hline & $\mathrm{g}_{X}$ & $0.6892 \times 10^{+01}$ & $0.4324 \times 10^{+01}$ & $0.4830 \times 10^{+01}$ & $0.7382 \times 10^{+01}$ \\
\hline & $\mathrm{g}_{Y}$ & $0.6773 \times 10^{+01}$ & $0.5484 \times 10^{+01}$ & $0.6206 \times 10^{+01}$ & $0.5933 \times 10^{+01}$ \\
\hline & $\mathrm{g}_{X Y}$ & $0.9663 \times 10^{+01}$ & $0.6984 \times 10^{+01}$ & $0.7864 \times 10^{+01}$ & $0.9471 \times 10^{+01}$ \\
\hline \multirow[t]{5}{*}{$\mathrm{KD}_{4}$} & $\mathrm{E}$ & 771.191 & 839.134 & 777.118 & 702.109 \\
\hline & $\mathrm{g}_{Z}$ & 10.0070 & 1.4123 & 10.7384 & 11.4744 \\
\hline & $\mathrm{g}_{X}$ & $0.5619 \times 10^{+00}$ & $0.7747 \times 10^{+01}$ & $0.2120 \times 10^{+00}$ & $0.1172 \times 10^{+01}$ \\
\hline & $\mathrm{g}_{Y}$ & $0.3491 \times 10^{+01}$ & $0.4659 \times 10^{+01}$ & $0.4074 \times 10^{+01}$ & $0.1979 \times 10^{+01}$ \\
\hline & $\mathrm{g}_{X Y}$ & $0.3536 \times 10^{+01}$ & $0.9040 \times 10^{+01}$ & $0.4080 \times 10^{+01}$ & $0.2300 \times 10^{+01}$ \\
\hline $\mathrm{KD}_{5}$ & $\mathrm{E}$ & 786.143 & 852.785 & 789.750 & 724.373 \\
\hline
\end{tabular}




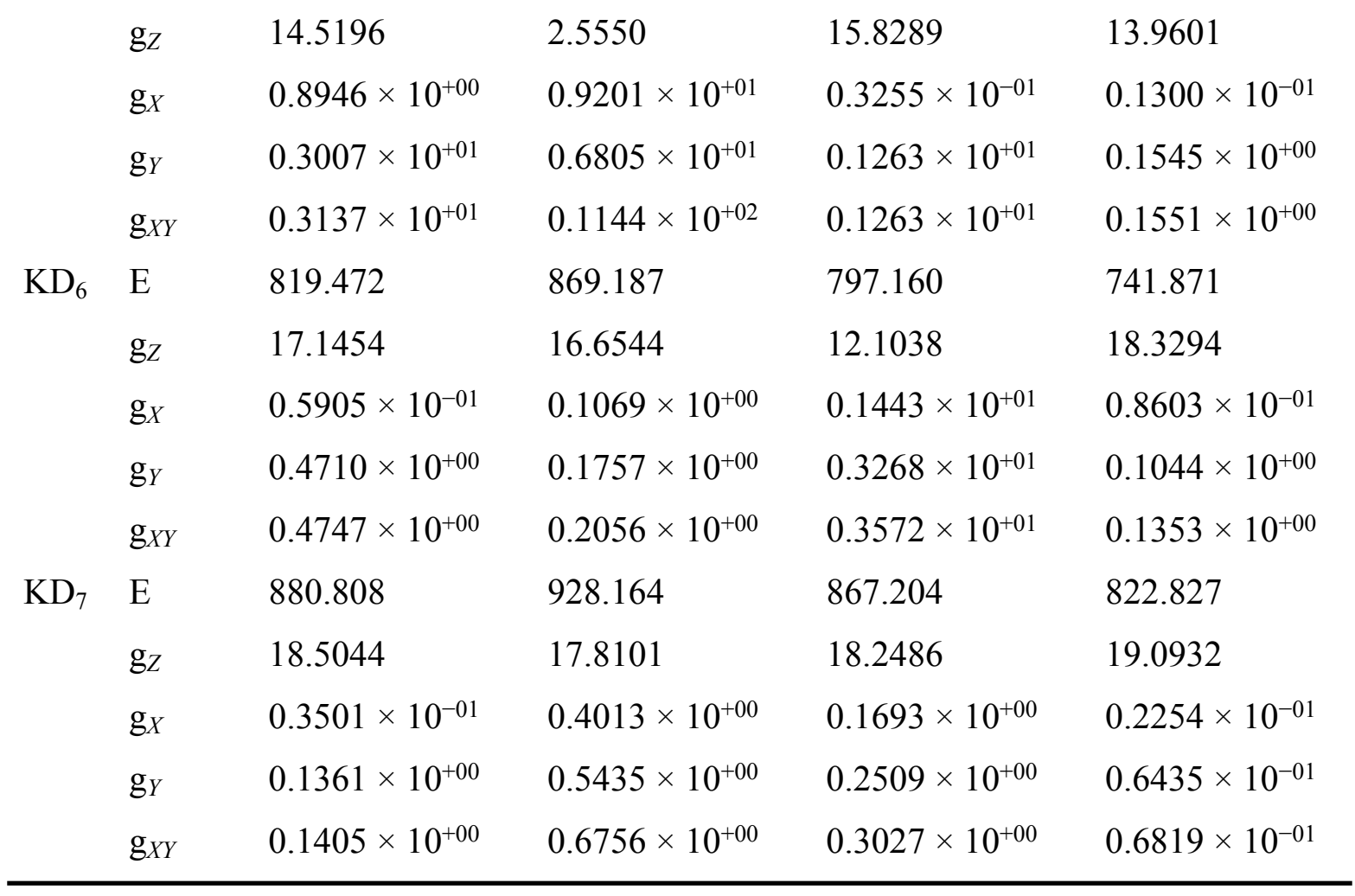

${ }^{a}$ Previous complexes reported by Tong's group.

Table S10 $U_{\text {eff }}$ (in $\mathrm{K}$ ) from both theoretical prediction and experimental fitting of the compounds here and those previously reported by Tong's group.

\begin{tabular}{lllll}
\hline & $\mathbf{1}$ & $\mathbf{2}$ & $\mathbf{2}^{\boldsymbol{a}}$ & $\mathbf{1}^{\boldsymbol{a}}$ \\
\hline $\exp$ & 837.7 & 1149.7 & 708.0 & 1025.0 \\
theo & 944.0 & 1158.0 & 860.0 & 1051.0 \\
\hline
\end{tabular}

Table S11 The LoProp charges (in |e|) from ab initio calculations and the lengths to central Dy ${ }^{3+}$ (in $\AA$ ) of the atoms in the first sphere ${ }^{a}$

\begin{tabular}{lllllllllll}
\hline & & $\mathrm{O}_{a x}-1$ & $\mathrm{O}_{a x}-2$ & $\mathrm{~N}_{e q u}-1$ & $\mathrm{~N}_{e q u}-2$ & $\mathrm{~N}_{e q u}-3$ & $\mathrm{~N}_{e q u}-4$ & $\mathrm{X}_{e q u}$ & $\mathrm{O}_{a v e}$ & $\mathrm{~N}_{a v e}$ \\
$\mathbf{1}$ & charge & -0.917 & -0.917 & -0.318 & -0.300 & -0.300 & -0.318 & -0.866 & -0.917 & -0.309 \\
& length & 2.160 & 2.160 & 2.568 & 2.585 & 2.585 & 2.568 & 2.669 & 2.160 & 2.576 \\
$\mathbf{1}{ }^{\boldsymbol{a}}$ & charge & -0.914 & -0.913 & -0.297 & -0.340 & -0.297 & -0.340 & -0.869 & -0.913 & -0.319 \\
& length & 2.166 & 2.167 & 2.587 & 2.579 & 2.587 & 2.579 & 2.682 & 2.166 & 2.584 \\
$\mathbf{2}$ & charge & -0.919 & -0.919 & -0.300 & -0.317 & -0.317 & -0.300 & 2.846 & -0.919 & -0.309 \\
& length & 2.155 & 2.155 & 2.578 & 2.583 & 2.583 & 2.578 & 2.682 & 2.155 & 2.580 \\
$\mathbf{2}^{\boldsymbol{a}}$ & charge & -0.914 & -0.914 & -0.301 & -0.342 & -0.342 & -0.301 & -0.848 & -0.914 & -0.322
\end{tabular}


a "ax" indicates the atoms at the axial positions, "equ" means the atoms at the equatorial positions, "ave" means the averaged value of the atoms of the same type, $\mathrm{X}$ of $\mathbf{1}$ and $\mathbf{1}$ ' are $\mathrm{Cl}$ atom while $\mathrm{X}$ of $\mathbf{2}$ and $\mathbf{2}$ ' are $\mathrm{Br}$ atom.

Table S12 The results of the preliminary ESP (in a.u.) analysis.

\begin{tabular}{lllll}
\hline complex & $\mathbf{1}$ & $\mathbf{1}^{\boldsymbol{a}}$ & $\mathbf{2}$ & $\mathbf{2}^{\boldsymbol{a}}$ \\
ESP(equ)/ESP(ax) & 0.824 & 0.843 & 0.778 & 0.807 \\
$\left|\frac{B(2,2)}{B(2,0)}\right|$ & 0.409 & 0.407 & 0.241 & 0.332 \\
ESP(ax) & -0.836 & -0.829 & -0.842 & -0.832 \\
ESP(equ) & -0.689 & -0.699 & -0.655 & -0.671 \\
ESP(equ_N) & 0.414 & 0.426 & 0.413 & 0.429 \\
ESP(equ_X) & 0.275 & 0.273 & 0.242 & 0.242 \\
\hline
\end{tabular}

${ }^{a}$ Previous complexes reported by Tong's group.
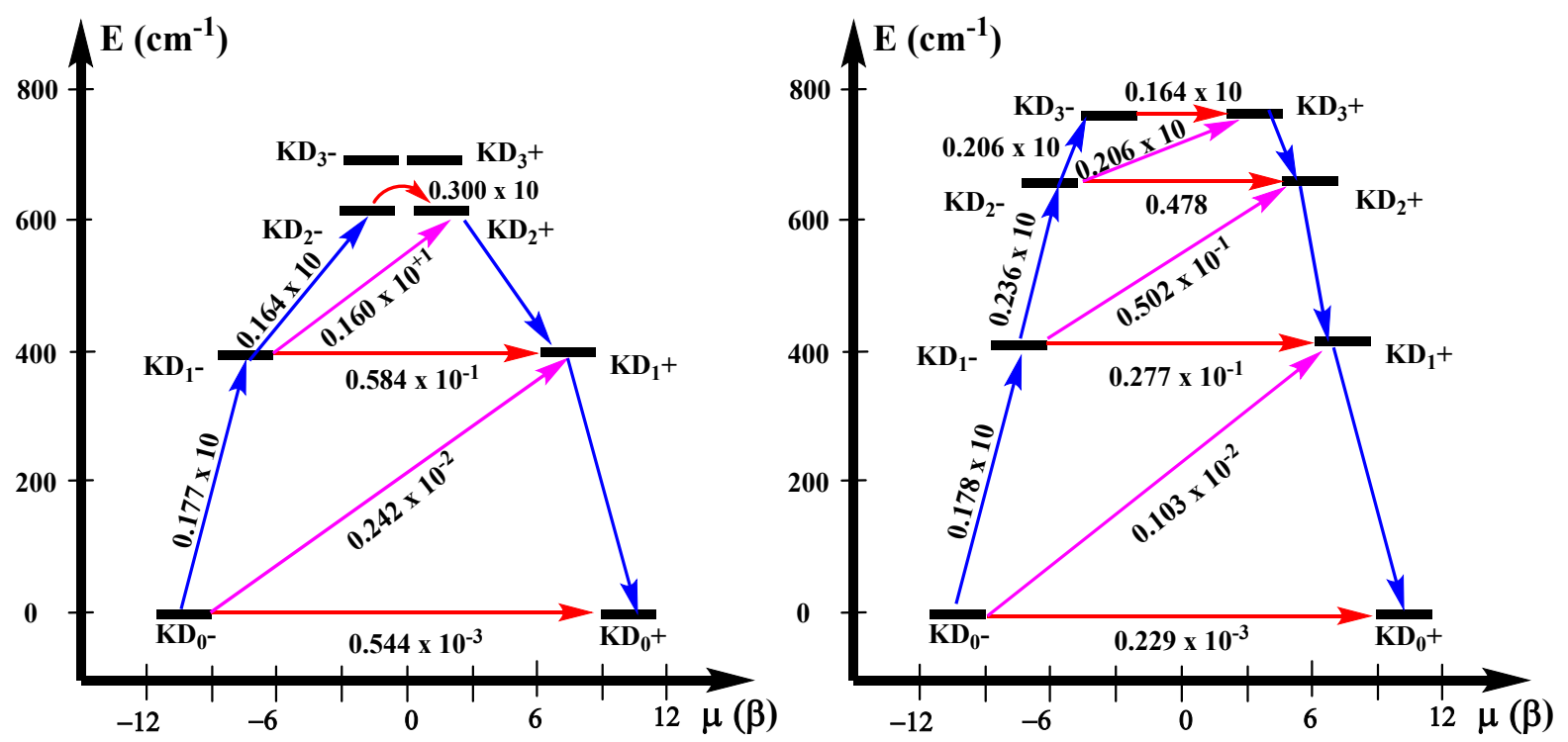

Figure S16. Ab initio predicted blocking barrier for the complexes $\mathbf{1}$ (left) and $\mathbf{2}$ (right) studied here. The red arrow indicates the possibility of QTM, and the blue and pink arrows indicate the possibilities of other processes of spin-phonon relaxation. 


\section{References}

[1] (a) Pinsky, Mark.; Avnir, David. Continuous Symmetry Measures. 5. The Classical Polyhedra. Inorg. Chem. 1998, 37, 5575-5582. (b) Zabrodsky, H.; Peleg, S.; Avnir, D. Continuous Symmetry Measures. J. Am. Chem. Soc. 1992, 114, 7843-7851.

[2] Luzón, J.; Sessoli, R. Lanthanides in molecular magnetism: so fascinating, so challenging. Dalton Trans. 2012, 41, 13556-13567.

[3] Roos, B. O.; Taylor, P. R.; Siegbahn, P. E. M. A complete active space SCF method (CASSCF) using a density matrix formulated super-CI approach. Chem. Phys. 1980, 48, 157-173.

[4] Aquilante, F.; Vico, L. De.; Ferré, N.; Ghigo, G.; Malmqvist, P.; Neogrády, P.; Pedersen, T. B.; Pitoňák, M.; Reiher, M.; Roos, B. O.; Serrano-Andrés, L.; Urban, M.; Veryazov, V.; Lindh, R. MOLCAS 7: the next generation. J. Comput. Chem. 2010, 31, 224-247.

[5] Aquilante, F.; Autschbach, J.; Carlson, R. K.; Chibotaru, L. F.; Delcey, M. G.; Vico, L. De.; Galván, I. F.; Ferré, N.; Frutos, L. M.; Gagliardi, L.; Garavelli, M.; Giussani, A.; Hoyer, C. E.; Manni, G. L.; Lischka, H.; Ma, D. X.; Malmqvist, Per-åke; Müller, T.; Nenov, A.; Olivucci, M.; Pedersen, T. B.; Peng, D. L.; Plasser, F.; Pritchard, B.; Reiher, M.; Rivalta, I.; Schapiro, I.; Segarra-Martií, J.; Stenrup, M.; Truhlar, D. G.; Ungur, L.; Valentini, A.; Vancoillie, S.; Veryazov, V.; Vysotskiy, V. P.; Weingart, O.; Zapata, F.; Lindh, R.; MOLCAS 8: New Capabilities for Multiconfigurational Quantum Chemical Calculations across the Periodic Table. J. Comput. Chem. 2016, 37, 506-541.

[6] Malmqvist, Per-åke.; Roos, B. O.; Schimmelpfennig, B. The restricted active space (RAS) state interaction approach with spin-orbit coupling. Chem. Phys. Lett. 2002, 357, 230-240.

[7] Hess, B. A.; Marian, C. M.; Wahlgren, U.; Gropen, O. A mean-field spin-orbit method applicable to correlated Wavefunctions. Chem. Phys. Lett. 1996, 251, 365-371.

[8] Roos, B. O.; Lindh, R.; Malmqvist, Per-åke.; Veryazov, V.; Widmark, Per-Olof. Main Group Atoms and Dimers Studied with a New Relativistic ANO Basis Set. J. Phys. Chem. A 2004, 108, 2851-2858.

[9] Roos, B. O.; Lindh, R.; Malmqvist, Per-åke.; Veryazov, V.; Widmark, Per-Olof. New relativistic ANO basis sets for transition metal atoms. J. Phys. Chem. A 2005, 109, 65756579 .

[10] Roos, B. O.; Lindh, R.; Malmqvist, Per-åke.; Veryazov, V.; Widmark, Per-Olof.; Borin, A. C. New Relativistic Atomic Natural Orbital Basis Sets for Lanthanide Atoms with Applications to the Ce Diatom and $\mathrm{LuF}_{3}$. J. Phys. Chem. A 2008, 112, 11431-11435. 
[11] Chibotaru, L. F.; Ungur, L. Ab initio calculation of anisotropic magnetic properties of complexes. I. Unique definition of pseudospin Hamiltonians and their derivation. J. Chem. Phys. 2012, 137, 064112.

[12] Chibotaru, L. F. Ab Initio Methodology for Pseudospin Hamiltonians of Anisotropic Magnetic Complexes, in Advances in Chemical Physics. Adv. Chem. Phys. 2013, 153, 397-519.

[13] Gatteschi, D.; Sessoli, R.; Villain. J. 5.1 Relaxation and relaxation time. In Molecular Nanomagnets, 2006, 160-161. Oxford University Press, Great Clarendon Street, Oxford OX2 6DP.

[14] Chibotaru, L. F. Theoretical understanding of anisotropy in molecular nanomagnets. Struct. Bond. 2015, 164, 185-229.

[15] Liddle, S. T.; van Slageren, J. Improving f-element single molecule magnets. Chem. Soc. Rev. 2015, 44, 6655-6669.

[16] Ungur, L.; Chibotaru, L. F. Strategies toward High-Temperature Lanthanide-Based SingleMolecule Magnets. Inorg. Chem. 2016, 55. 10043-10056.

[17] Bartolomé, E.; Arauzo, A.; Luzón, J.; Bartolomé, J.; Bartolomé, F. Magnetic Relaxation of Lanthanide-Based Molecular Magnets. In Handbook of Magnetic Materials, 2017, 26, chapter 1. Elsevier B.V.

[18] Li, M.; Wu, H. P.; Yang, Q.; Ke, H. S.; Yin, B.; Shi, Q.; Wang, W. Y.; Wei, Q.; Xie, G.; Chen. S. P. Experimental and Theoretical Interpretation on the Magnetic Behavior in a Series of Pentagonal-Bipyramidal Dy ${ }^{\mathrm{III}}$ Single-Ion Magnets. Chem. Eur. J. 2017, 23, 17775-17787.

[19] Yin, B.; Li, C. C. A method to predict both the relaxation time of quantum tunneling of magnetization and the effective barrier of magnetic reversal for a Kramers single-ion magnet. Phys. Chem. Chem. Phys. 2020, 22, 9923-9933.

[20] Gatteschi, D.; Sessoli, R.; Villain. J. 5.6 Transition probability and the golden rule. In Molecular Nanomagnets, 2006, 171-173. Oxford University Press, Great Clarendon Street, Oxford OX2 6DP.

[21] Liu, J. L.; Chen, Y. C.; Tong, M. L. Symmetry strategies for high performance lanthanidebased single molecule magnets. Chem. Soc. Rev. 2018, 47, 2431-2453.

[22] Gatteschi, D.; Sessoli, R.; Villain. J. 5.5 Spin-phonon interaction. In Molecular Nanomagnets, 2006, 167-171. Oxford University Press, Great Clarendon Street, Oxford OX2 6DP. 
[23] Gatteschi, D. Sessoli, R. Quantum Tunneling of Magnetization and Related Phenomena in Molecular Materials. Angew. Chem. Int. Ed. 2003, 42, 268-297.

[24] Escalera-Moreno, L.; Suaud, N.; Gaita-Ariño, A.; Coronado, E. Determining Key Local Vibrations in the Relaxation of Molecular Spin Qubits and Single-Molecule Magnets. $J$. Phys. Chem. Lett. 2017, 8, 1695-1700.

[25] Lunghi, A.; Totti, F.; Sessoli, R.; Sanvito, S. The role of anharmonic phonons in underbarrier spin relaxation of single molecule magnets. Nat. Commun. 2017, 8, 14620.

[26] Lunghi, Alessandro.; Totti, F.; Sanvito, S.; Sessoli, R. Intra-molecular origin of the spinphonon coupling in slow-relaxing molecular magnets. Chem. Sci. 2017, 8, 6051-6059.

[27] Le Tuan Anh Ho and Liviu F. Chibotaru. Multiple relaxation times in single-molecule magnets. Phys. Rev. B 2016, 94, 104422.

[28] Conrad, A. P. Goodwin, F. O.; Reta, D.; Chilton, N. F.; Mills, D. P. Molecular magnetic hysteresis at 60 kelvin in dysprosocenium. Nature 2017, 548, 439-442.

[29] Alonso, P. J.; Mart'inez, J. I. Magnetic properties of a Kramers doublet. An univocal bridge between experimental results and theoretical predictions. J. Magn. Reson. 2015, 255, 114.

[30] Ungur, L.; Chibotaru, L. F. Magnetic anisotropy in the excited states of low symmetry lanthanide complexes. Phys. Chem. Chem. Phys. 2011,13, 20086-20090.

[31] Ungur, L.; Chibotaru, L. F. Computational Modelling of the Magnetic Properties of Lanthanide Compounds. In Richard A Layfield and Muralee Murugesu, editors, Lanthanides and Actinides in Molecular Magnetism, 2015, 6, 153-184. Wiley-VCH Verlag GmbH \& Co. KGaA, first edition.

[32] Liu, J.; Chen, Y. C.; Liu, J. L.; Vieru, V.; Ungur, L.; Jia, J. H.; Chibotaru, L. F.; Lan, Y.; Wernsdorfer, W.; Gao, S.; Chen, X. M.; Tong, M. L. A stable pentagonal bipyramidal Dy(III) single-ion magnet with a record magnetization reversal barrier over $1000 \mathrm{~K} . J$. Am. Chem. Soc. 2016, 138, 5441-5450.

[33] Aravena, D. Ab Initio Prediction of Tunneling Relaxation Times and Effective Demagnetization Barriers in Kramers Lanthanide Single-Molecule Magnets. J. Phys Chem. Lett. 2018, 9, 5327-5333.

[34] Llanos, L.; Aravena, D. Relaxation time enhancement by magnetic dilution in singlemolecule magnets: An ab initio study. J. Magn. Magn. Mater. 2019, 489, 165456.

[35] Sievers, J. Asphericity of 4f-Shells in Their Hund"s Rule Ground States. Z. Phys. B 1982, 45, 289-296. 
[36] Rinehart, J. D.; Long, J. R. Exploiting single-ion anisotropy in the design of f-element single-molecule magnets. Chem. Sci, 2011, 2, 2078-2085.

[37] Zhang, S.; Wu, H. P.; Sun, L.; Ke, H. S.; Chen, S. P.; Yin, Bing.; Wei, Q.; Yang, D. S.; Gao, S. L. Ligand field fine-tuning on the modulation of the magnetic properties and relaxation dynamics of dysprosium(III) single-ion magnets (SIMs): synthesis, structure, magnetism and ab initio calculations. J. Mater. Chem. C 2017, 5, 1369-1382.

[38] Jiang, Z. J.; Sun, L.; Yang, Q.; Yin, B.; Ke, H. S.; Han, J.; Wei, Q.; Xie, G.; Chen, S. P. Excess axial electrostatic repulsion as a criterion for pentagonal bipyramidal Dy ${ }^{\mathrm{III}}$ singleion magnets with high $U_{\text {eff }}$ and $T_{\mathrm{B}} . J$. Mater. Chem. C. 2018, 6, 4273-4280.

[39] Guo, M.; Wu, J. F.; Cador, Ol.; Lu, J. J.; Yin, B.; Guennic, B. L.; Tang, J. K. Manipulating the Relaxation of Quasi- $D_{4 \mathrm{~d}}$ Dysprosium Compounds through Alternation of the O-Donor Ligands. Inorg. Chem. 2018, 57, 4534- 4542.

[40] Ungur, L.; Chibotaru, L. F. Ab Initio Crystal Field for Lanthanides. Chem. Eur. J. 2017, 23, 3708-3718.

[41] Huang, G. Z.; Ruan, Z. Y.; Zheng, J. Y.; Chen, Y. C.; Wu, S. G.; Liu, J. L.; Tong, M. L. Seeking magneto-structural correlations in easily tailored pentagonal bipyramid Dy(III) single-ion magnets. Sci. China Chem. 2020, 63, 1066-1074. 